IZA DP No. 4379

A Microsimulation Approach to an Optimal Swedish Income Tax

Peter Ericson

Lennart Flood

August 2009 


\title{
A Microsimulation Approach to an Optimal Swedish Income Tax
}

\author{
Peter Ericson
}

Empirica

\author{
Lennart Flood \\ University of Gothenburg \\ and IZA
}

Discussion Paper No. 4379

August 2009

IZA

P.O. Box 7240

53072 Bonn

Germany

Phone: +49-228-3894-0

Fax: +49-228-3894-180

E-mail: iza@iza.org

Any opinions expressed here are those of the author(s) and not those of IZA. Research published in this series may include views on policy, but the institute itself takes no institutional policy positions.

The Institute for the Study of Labor (IZA) in Bonn is a local and virtual international research center and a place of communication between science, politics and business. IZA is an independent nonprofit organization supported by Deutsche Post Foundation. The center is associated with the University of Bonn and offers a stimulating research environment through its international network, workshops and conferences, data service, project support, research visits and doctoral program. IZA engages in (i) original and internationally competitive research in all fields of labor economics, (ii) development of policy concepts, and (iii) dissemination of research results and concepts to the interested public.

IZA Discussion Papers often represent preliminary work and are circulated to encourage discussion. Citation of such a paper should account for its provisional character. A revised version may be available directly from the author. 
IZA Discussion Paper No. 4379

August 2009

\section{ABSTRACT}

\section{A Microsimulation Approach to an Optimal Swedish Income Tax}

This paper follows the theory of optimal taxation and the goal is to identify a tax/benefit design that maximizes social welfare. A two stage process is proposed where the individuals preferred choice of leisure and consumption is solved in the first stage, and the second stage identifies the tax/benefit system that maximize the social welfare function. Our study deviates from the mainstream literature as the first stage is based on a static micro simulation model with behavioral responses. The behavioral responses take two different forms and use two different types of models; first binary models that describe mobility in/out from non-work states such as old age pension, disability, unemployment, long term sickness, and second models that describe change in working hours and welfare participation. Compared to the current Swedish income tax, our results suggest that increased basic deduction and in-work tax credit in combination with a reduction of the progressive national taxes would increase welfare. We also find strong support for increased housing allowances. The reforms are financed by a tax based on the same tax base as the proportional municipal income tax.

JEL Classification: $\quad$ C8, D31, H24

Keywords: micro simulation, tax-benefit system, in-work tax credit reform, optimal taxation

Corresponding author:

Lennart Flood

School of Business, Economics and Law

University of Gothenburg

P.O. Box 640

SE 40530 Göteborg

Sweden

E-mail: Lennart.Flood@economics.gu.se

\footnotetext{
* Financial support from the Jan Wallander and Tom Hedelius Foundation for Research in Economics and from the Confederation of Swedish Enterprise is gratefully acknowledged. We also like to express our gratitude towards Rolf Aaberge for his support and constructive criticism.
} 


\section{Introduction}

In a recent study Aaberge \& Colombino (2008) applied the method of microsimulation to the problem of selecting an optimal Norwegian income tax design. This paper focuses on the Swedish income tax/benefit system and extends the Aaberge \& Colombino study in several dimensions. ${ }^{2}$ First individuals outside the labor force are included in the population at risk. The tax/benefit model includes benefits from unemployment, disability, long term sickness as well as old age pension. Thus, entries/exits between non-work states and work states are considered in the analyses. This is of particular importance when including effects of in-work tax credit reforms that has become a popular trend in many OECD countries, see Owens (2005). Also, apart from taxes, this study includes changes in transfer systems such as housing and child allowances. An important component in the analyses is the combination of tax/benefit system considered. In contrast to Aaberge \& Colombino that used a parameterization of a piecewiselinear tax-system our approach is more related to choosing among politically feasible tax/benefit systems. This is done partly by choosing from a menu of historical taxes during the period 1983 to 2009 . Since the historical tax schemes show a wide variability a large range of realistic tax designs are covered. Apart from historical taxes, the tax and benefit rules in 2006 is regarded as a reference, and then a number of modifications are considered, such as changes in levels, brackets and tax credits/deductions as well as changes in benefits. Finally, inspired by the optimal tax literature we also evaluate taxes that are age dependent as well as one variant where the marginal tax rate is set to zero at the highest income. Of all these tax/benefit packages we identify the system that maximizes a social welfare function.

It is instructive to contrast the method of microsimulation to the mainstream method of calibrated models used in the optimal taxation literature. The microsimulation method permits an exact description of the tax/benefit system, allows for a detailed specification of the labor supply model including observed as well as unobserved heterogeneity and also considers the simultaneous decisions of household members. The micro-approach allows for distributional analyses as well as aggregated measures. As in the theory of optimal taxation the goal is to search for a system of taxation that minimizes the welfare cost. As well as in the optimal taxation literature there is a two stage process where the individuals preferred choice of leisure and consumption is solved in the first stage and the second choice identifies the tax/benefit system

\footnotetext{
${ }^{2}$ For practical reasons income tax is used as a synonymous for tax on earnings, taxes on capital are not included in this analyses.
} 
that maximize the social welfare function. There has been many insights from the optimal income tax literature ${ }^{3}$ such that based on equity, income taxes should be higher for those with greater income and based on efficiency, marginal tax rates should be lower the more responsive individuals are in their labor decisions. However, the practical applicability has been limited since it ignores a range of issues that are important in the analysis of taxation. Admittedly, later contributions have reached a higher level of pragmatism and therefore also a higher policy relevance. One reference is Saez (2001) in which the classical theorems are formulated in terms of supply elasticities which create a link between theory and empirical application. In Saez (2002) an optimal tax design is derived based on supply elasticities considering hours at both the extensive as well as intensive margin. Similarly to our study Immervol et al. (2005) is also based on a microsimulation model (EUROMOD), however this model covers a large number of countries in the European Union. According to their findings, given reasonable welfare weights, the in-work tax credit is an optimal design for most countries. Finally Blundell \& Shephard (2008) gives an interesting illustration of the state of the art in optimal taxation. Their approach is based on estimated labor supply models (similar to models used in this paper), they include both extensive and intensive margin (as we do) but different from our study they use a simplified tax system.

However, even if the current literature in optimal taxation represent a more realistic approach, much of the critique expressed in Slemrod (1990) is still relevant. Factors like administrative cost, tax planning and avoidance, simplicity and transparence that plays an important role in the design of a tax system is not typically considered. Even though this critique also is applicable to the microsimulation method, this method still offers a higher flexibility in implementing complicated and more realistic tax structures therefore the microsimulation approach offers an interesting contrast to the calibrated models used in the optimal taxation literature. For a detailed description of the model used in this report we refer to Ericson, Flood \& Wahlberg (2009). The next section starts with a short summary of the model and a presentation of the social welfare function. Section 3 describes the method used when choosing an optimal tax/benefit system. Section 4 gives a short history of the Swedish income tax system along with a closer look at 2006 years system. Section 5 describes the design of the tax/benefit systems

\footnotetext{
${ }^{3}$ See e.g Mirrlees (1971), Stern (1987), Gruber and Saez (2002), Laroroque (2005)
} 
evaluated and the results of the simulations are presented next. The paper ends with a summary and conclusion.

\section{The microsimulation model}

Microsimulation models can be classified according to a large number of characteristics, from completely static to fully dynamic life-cycle models. For a recent survey of the microsimulation literature see e.g O'Donoghue (2001) or Merz (1991). Static models do not attempt to incorporate behavioral change, and are used to calculate the immediate impact of institutional changes in the tax and benefit system. FASIT is an example of a static tax-benefit model developed by Statistics Sweden and used by the Swedish ministry of finance. EUROMOD is an extension of these models applicable to the EU-countries. ${ }^{4}$ In principle these models are only a detailed description of the tax and benefit system, but behavioral effects can be integrated. Immervoll et. al. (2008) provides an interesting example of behavioral relations included in EUROMOD and the analyses in this paper is based on incorporating behavioral models in a modified version of FASIT, we refer to this model as SWEtaxben (see Ericson, Flood \& Wahlberg (2009)).

Relating to the micro simulation literature SWEtaxben can be labeled as a static micro simulation model with behavioral changes. Thus, unlike a pure static model SWEtaxben allows for a change in individual behavior as a response to a change in economic incentives. This behavioral response takes two different forms and use two different types of models; first binary models that describe mobility in/out from non-work states such as old age pension, disability, unemployment, long term sickness, and second models that describe change in working hours and welfare participation. Thus, apart from the choice to work or not to work (extensive margin), working hours conditional on working (intensive margin) as well as welfare participation are treated as endogenous variables.

The data used for the simulations are based on 2006 year LINDA, the sample size correspond to almost $8 \%$ of the Swedish population, thus all the output is given with a high

\footnotetext{
${ }^{4}$ For a survey of static micro simulation models in Europe, see Sutherland (1995)
} 
precision and since the sampling weights are known aggregate population measures can be produced. ${ }^{5}$

The tax/benefit part of SWEtaxben is primarily a tool for calculation of household budget sets. For the two earners household the budget (disposable income or net income after tax and transfers) evaluated at observed working hours is given as

$$
\mathrm{C}=\mathrm{I}_{\mathrm{m}}+\mathrm{I}_{\mathrm{f}}+\mathrm{B}_{\mathrm{s}}+\mathrm{B}_{\mathrm{h}}-\mathrm{B}_{\mathrm{c}} \quad \text { where } \mathrm{I}_{\mathrm{i}}=\mathrm{W}_{\mathrm{i}} \mathrm{H}_{\mathrm{i}}+\mathrm{Y}_{\mathrm{i}}+\mathrm{V}_{\mathrm{i}}-\mathrm{t}\left(\mathrm{X}_{\mathrm{i}}\right), \mathrm{i}=\mathrm{m} \text { (male), } \mathrm{f}(\text { female) }
$$

Apart, from hourly wages, $\mathrm{W}_{\mathrm{i}}$ and yearly working hours, $\mathrm{H}_{\mathrm{i}}, \mathrm{Y}_{\mathrm{i}}$ represent non-earned taxable income (e.g. capital income, old age pension and benefits from unemployment, disability and long term sickness) and $V_{i}$ non-earned non-taxable income (e.g. child allowance), $t$ is a tax function defined on taxable income, $\mathrm{X}_{\mathrm{i}},\left(\mathrm{X}_{\mathrm{i}}=\mathrm{W}_{\mathrm{i}} \mathrm{H}_{\mathrm{i}}+\mathrm{Y}_{\mathrm{i}}-\mathrm{D}_{\mathrm{i}}\right.$, where $\mathrm{D}_{\mathrm{i}}$ is deductions for work related expenses or part of premium for private pension savings). The three means-tested (that is dependent on $\mathrm{H}_{\mathrm{i}}$ ) transfers considered are social assistance $\left(\mathrm{B}_{\mathrm{s}}\right)$, housing allowance $\left(\mathrm{B}_{\mathrm{h}}\right)$ and cost of child care $\left(\mathrm{B}_{\mathrm{c}}\right)$. It is a considerable advantage that these systems are based on nationwide rules.

In order to understand the different steps involved in the simulation it is instructive to start by dividing the sample in the following subgroups;

(1) Child, 0-15 years of age, (2) Old age pensioner, from age 61-, (3) Student, (4) Disability pensioner, 18-64 and old age pensioner after 64, (5) Parental leave, (6) Unemployed, 18-64 and old age pensioner after 64, (7) Other (no income from states 2-6, 8, 9 but can have income from social assistance), (8) Long term sick, 18-64 and old age pensioner after 64 and (9) Working, 1870 and old age pensioner after 70 .

This classification refers to a full time status during the base year (2006) and is primarily based on the main source of income. If an individual gets the largest part from old age pension then he is classified as a pensioner, if it comes from disability pension then he is classified as disabled and so on. There are also some age related criteria that overrules the income source. Thus all individuals less than 16 are classified as a child and all individuals above 70 as an old

\footnotetext{
${ }^{5}$ For a description of LINDA see Edin \& Fredriksson (2000).
} 
age pensioner. An individual can only be classified as disabled, unemployed or long term sick up to 64 year of age, above that he is classified as an old age pensioner.

The main sequential steps are given in Figure 1 below. The steps described below will be the same both for the simulation before as after a reform, the only difference is changes in tax/benefit rules. First step (see Figure 1) involves the definition of replacement rate for disability pension. The population at risk is individuals age 18-64 (but not older children living together with their parents) with status disabled/unemployed, long term sick or working. For couples at least one of the spouses should belong to the population at risk. For each individual in this population the tax/benefit module is called to calculate disposable income assuming that everyone is classified as on full time disability. Next, for same individuals, income is calculated assuming full time work $(\mathrm{H}=1800)$. The ratio, disposable income from disability divided by disposable income from work, is the replacement rate. For instance a replacement rate of 0.7 means that an individual who receives full time compensation from disability insurance, receive 70 percent of the disposable income as he would have as a full time worker. A change in a tax/benefit that has an effect on the replacement rate will also have an effect on the probability of entry, staying in, or exit from disability.

Given the replacement rate, as well as all other explanatory variables included in the model, the probability of disability is calculated. In the calculation of this probability two stochastic terms enter, first a random draw from a normal distribution (with an estimated mean and variance) representing individual heterogeneity and second a Monte Carlo experiment. If the simulated probability is less than a random draw from a uniform (0-1) distribution, then the event takes place; that is, the individual is classified as disabled. Note that the random errors for each individual are the same before and after a reform. Individuals not classified as disabled get the temporary status (10) and enter the next stochastic model in the sequence. The Monte Carlo experiment acknowledge the fact that even individuals whose characteristic are such that the likelihood of disability are very low still faces the risk of "bad luck". With appropriate changes the same argument also applies to an individual with a high systematic probability of disability. This stochastic experiment has been applied to all binary events in the model.

Next step involves unemployment and the population at risk is unemployed, long term sick, working and those belonging to the temporary status. The steps involved are the same as for 
disability, thus after this step the individuals in the risk population are either classified as unemployed or in the temporary state. After this follows the long term sick, the population at risk is now long term sick, working and in the temporary state. Again same procedure and as a result of this module individuals are in the status long term sick or temporary. The final binary model is old age pension; the population at risk is old age pensioner, other, working or temporary status at age 61-70. An individual below 61 is not eligible for old age pension and all individuals above 70 are by default old age pensioners. Again after this step individuals are classified as old age pensioners or in the temporary state.

After these binary models a simple imputation follows, all individuals with the temporary status who before the reform belonged to one of the binary states, that is individuals who have exit from one of the binary states, are imputed as entering the working state and are given a working hour equal to 1800 . Note, this does not mean that an individual that for instance belong to disability (before the reform) and predicted to exit disability is given $\mathrm{H}=1800$. However, if this individual will pass the remaining three binary states and still be predicted as an exit, then he will get $\mathrm{H}=1800$. This concludes the first part of the model where the binary models are used. Next we will explain the imputation of working hours and social assistance.

Every individual in the risk population (status other or working) are considered as working or voluntarily non-working. Thus, this is the typically risk population in traditionally labor supply studies. For every individual in this population the tax/benefit module is called upon repeatedly in order to evaluate the budget set. For individuals classified as singles this requires 14 calls (7 working classes with and without social assistance) and for couples the creation of the budget set requires 98 calls $(7 * 7 * 2)^{6}$. Note that for the couples at least one of the spouses should belong to the population at risk. Given the budget set and all other variables included in the labor supply models, working hours as well as the probability of social assistance is predicted. The stochastic experiment for those models involves draws from an extreme value distribution. Also note that different models have been estimated depending on the family type.

At this stage of the simulation every individual has a predicted status as well as working hours and welfare participation. A final step is to call the tax/benefit module again to get the

\footnotetext{
${ }^{6}$ Of course in practice the tax/benefit module is evaluated 7 times for singe and 49 for spouses and each time disposable income with and without social assistance is calculated.
} 
predicted disposable income, calculated at predicted status and working hours. Thus, this is the predicted disposable income for the individuals/households that are the results of the tax/benefit rules, by changing these rules and repeating the simulation disposable income before and after a reform can be compared.

Of course the results of the simulations are dependent on the econometric models and for this reason a short presentation follows in next section, and again for a detailed presentation we refer to Ericson et. al (2009).

\subsection{Binary models of occupational status}

As mentioned above four econometric models are included in the simulation of the probability of disability, unemployment, long term sickness and old age pension. All of these models have been estimated as dynamic random-effects logit models. The data used for the estimation is a balanced LINDA panel from 2000-2006.

Following Wooldridge (2002, 2005) we define the model,

$$
y_{i t}=1\left\{\rho y_{i t-1}+\beta_{1} x_{1 i t}+\beta_{2} x_{2 i t}+\cdots+\beta_{k} x_{k i t}+c_{i}+\varepsilon_{i t}\right\}
$$

where,

$$
\begin{aligned}
& c_{i}=\alpha_{0}+\alpha_{1} y_{i 0}+\gamma_{1} \bar{x}_{1 i}+\gamma_{2} \bar{x}_{2 i}+\cdots+\gamma_{m} \bar{x}_{m i}+\mu_{i} \\
& \text { with, } \\
& \varepsilon_{i t} \sim N(0,1) \text { and } \mu_{i} \sim \text { logistic }
\end{aligned}
$$

where $y_{i t}$ denote the occupational status of individual i year $\mathrm{t}$ ( 1 if individual is disabled, unemployed and so on), $\mathrm{y}_{\mathrm{it}-1}$ is the occupational status the previous year and the $\mathrm{x}$-variables are measures of observed characteristics, like age, education and so on. Unobserved determinants are time-invariant, $\mathrm{c}_{\mathrm{i}}$, or time-variant $\varepsilon_{\mathrm{it}}$. The time-invariant unobserved component $\mathrm{c}_{\mathrm{i}}$ is allowed to be correlated with the occupational status of the initial period and the time-average of the explanatory variables. The purpose is to address the initial conditions problem and the possible endogeneity of explanatory variables with respect to time-invariant characteristics. The $\bar{x}$ variables denote the average value for the time invariant variables for each individual. 
The variables included in the different models are given in Figure 1 but also note that a more detailed description of the estimated models are included in Ericson et. al. (2009).

\subsection{The labor supply model}

We model labor supply as a discrete choice, following previous work by van Soest (1995); the household model is described in Flood et. al. (2004) and the model for the single headed household in Flood et. al. (2007). The discrete choice model allow us to include as many details as needed regarding the budget set and it extends naturally into a household model, where husbands and wives jointly determine their labor supply. Specifically, we assume that each individual can choose among seven alternatives in the choice set of income-leisure combinations and hence the choice set for a household contains $7 * 7$ different hours of work combinations.

We assume that family utility depends not only on consumption and leisure, but also on participation in social assistance. We further assume that the utility function is increasing in income and leisure and decreasing in welfare participation. The disutility from participation in social assistance is assumed to reflect the non-monetary costs, such as fixed costs or "stigma", and is included to account for nonparticipation among eligible families. ${ }^{7}$

Following van Soest (1995), we use a trans-log specification of the direct utility function, and for any specific household we have:

$$
\begin{aligned}
& U\left(C, T-h_{j}\right)=\alpha_{1} \log C+\alpha_{11}(\log C)^{2}+\alpha_{2}\left(\log \left(T-H_{H}\right)\right)+\alpha_{22}\left(\log \left(T-H_{H}\right)\right)^{2} \\
& +\alpha_{3}\left(\log \left(T-H_{W}\right)\right)+\alpha_{33}\left(\log \left(T-H_{W}\right)\right)^{2}+\alpha_{12} \log C^{*}\left(\log \left(T-H_{H}\right)\right) \\
& +\alpha_{13} \log C^{*}\left(\log \left(T-H_{W}\right)\right)+\alpha_{23}\left(\log \left(T-H_{H}\right)\right) *\left(\log \left(T-H_{W}\right)\right)- \\
& \alpha_{4} P_{S A}-b_{f c h} D_{H}-b_{f c w} D_{W}
\end{aligned}
$$

and for single headed household as:

$$
\begin{aligned}
& U\left(C, T-h_{j}\right)=\alpha_{1} \log C+\alpha_{11}(\log C)^{2}+\alpha_{2}\left(\log \left(T-H_{H}\right)\right)+\alpha_{22}\left(\log \left(T-H_{H}\right)\right)^{2} \\
& +\alpha_{12} \log C^{*}\left(\log \left(T-H_{H}\right)\right)-\alpha_{4} P_{S A}-b_{f c} D_{w}
\end{aligned}
$$

\footnotetext{
${ }^{7}$ What may appear as "stigma" or disutility from welfare participation may also result from errors in measuring true welfare eligibility. Moreover, imperfect information regarding benefit eligibility on behalf of the household is also included in this nonmonetary cost.
} 
where $C$ is household disposable income described above and $\left(T-H_{j}\right)$ is leisure $(j=M$, (male) or $\mathrm{F}$ (female)) and $\mathrm{T}$ is an upper limit (4 000) $\mathrm{P}_{\mathrm{SA}}$ is a binary variable, taking the value one if the household is a receiver of social assistance else zero. $D_{j}$ is also a binary variable, taking the value one if working hours is above zero, reflecting the importance of "fix cost" of working.

In order to implement the model, we also have to specify the nature of heterogeneity in household preferences and the stochastic disturbances. For the household model heterogeneity in preferences for leisure is introduced as,

$$
\begin{aligned}
& \text { (5) } \quad \alpha_{2}=\sum_{k=1}^{K} \alpha_{2, k} z_{2, k}+\phi_{H} \\
& \text { (6) } \alpha_{3}=\sum_{k=1}^{K} \alpha_{3, k} z_{3, k}+\phi_{W}
\end{aligned}
$$

and in the specification of welfare participation as,

$$
\alpha_{4}=\sum_{j=1}^{J} \alpha_{4, j} z_{4 j}+\phi_{S A}
$$

The corresponding specifications for the single person is given by,

$$
\begin{aligned}
& \alpha_{2}=\sum_{k=1}^{K} \alpha_{2, k} z_{2, k}+\phi_{H} \\
& \alpha_{4}=\sum_{j=1}^{J} \alpha_{4, j} z_{4 j}+\phi_{S A}
\end{aligned}
$$

The z-vector includes measurable individual and household characteristics and the $\phi^{\prime} \mathrm{s}$ represents unobserved variables that affect preferences for leisure. As usual it is assumed that an important source for population heterogeneity in terms of preferences for leisure is unobserved. In order to account for this, we formulate a finite mixture model, which allows for unobserved heterogeneity in a very flexible way without imposing a parametric structure. To make the model estimable, additional random disturbances are added to the utilities of all choice opportunities (for details see Flood et. al. (2004) and (2007)).

In the estimation seven different classes or intervals of working hours per year have been used; 0, 1-500, 501-1000, 1001-1500, 1501-2000, 2001-2500, and above 2500.

Since the parameters in these highly non-linear models do not have a simple 
interpretation, Table 1 below presents wage elasticities. These are within the bounds typically presented in the literature, higher for females and a negative male-female cross elasticity.

(Table 1. Uncompensated wage elasticities by family type)

\subsection{The social welfare function ${ }^{8}$}

So far we have not discussed a suitable measure that can be used to characterize the welfare benefits of a reform. Even though it is relevant to measure the change in level or distribution of disposable income this is not an ideal measure when evaluating whether a reform should be preferred or not. For instance, a reform such as an in-work tax credit and decreased state tax that is evaluated below is found to both increase the level of income as well as reduce the inequality of the income distribution. Although this can be judged as an improvement it does not necessarily imply increased welfare for every individual. The reason is that some households have increased their income due to increased working hours whereas others have obtained higher income without increased hours. Since we assume that working hours is a disutility the increase in income and decrease in leisure might very well result in a much smaller increase in welfare compared to the corresponding increase in disposable income. For this reason a social welfare function is estimated and will be used as one criterion in the evaluation of a reform.

We introduce the idea of a social planner who wants to implement a tax/benefit design to optimize welfare. The well known problem of interpersonal comparability is solved by assuming the existence of a common individual welfare function which is assumed to increase in income and leisure. The formal definition of the individual welfare function $(\Psi)$ determined by the social planner is given by

$$
\Psi_{\mathrm{i}}=\mathrm{f}\left(\mathrm{L}_{\mathrm{i}}, \mathrm{C}_{\mathrm{i}}\right)
$$

where $\mathrm{L}$ is leisure and $\mathrm{C}$ is disposable income. The simplest measure of aggregate welfare is simply to sum all individuals' measure of welfare. However, since this implies equal welfare

\footnotetext{
${ }^{8}$ This section is largely based on Aaberge and Flood (2008) and Aaberge and Colombino (2008) and for details we refer to these sources.
} 
weights to the individuals, independent of the welfare level, this specific welfare function ignores distributive considerations. In order to address distributive justice individuals with a low welfare should be assigned larger welfare weights than those that are better off. This is described by the following family of rank-dependent welfare functions,

$$
W_{k}=\frac{1}{N} \sum_{i=1}^{N} p_{k}\left(\frac{i}{N}\right) \Psi_{i}, \quad k=1,2, \ldots
$$

where $\Psi_{1} \leq \Psi_{2} \leq \ldots \leq \Psi_{N}$ is the ordered individual welfare levels $\Psi$, and $p_{k}(t)$ is a weight function defined by

$$
p_{k}(t)=\left\{\begin{array}{ll}
-\log t, & k=1 \\
\frac{k}{k-1}\left(1-t^{k-1}\right), & k=2,3, \ldots
\end{array} \quad 0<t \leq 1\right.
$$

The implication of (11) is that the weights given to low-welfare individuals decrease with increasing $\mathrm{k}$. As $k \rightarrow \infty, W_{k}$ approaches inequality neutrality and coincides with the linear additive welfare function defined by

$$
W_{\infty}=\frac{1}{N} \sum_{i=1}^{N} V_{i}
$$

To provide a simple guide to understand the inequality aversion profiles exhibited by $W_{1}$, $W_{2}, W_{3}$ and $W_{\infty}$ Table 2 provides ratios of the corresponding weights - as defined by (11) - of the median individual and the one percent poorest, the five percent poorest, the thirty percent poorest and the five percent richest individual for different social welfare criteria.

\section{(Table 2. Distributional weight profiles of four different social welfare functions)}

\subsection{Estimation of the Social welfare function}

The welfare function can be estimated either on household or on individuals. In either case the problem of comparing single- and non-single household must be solved. In Aaberge et. al. (2008) the welfare measure is based on individuals and in order to make individuals in couple and single household comparable the disposable income of the couple is divided by the square root of two. In this study we choose the household as the unit for estimation and welfare 
evaluation. We do this by transforming a couple-household into one representative household by using the average of disposable income (C) and working hours (H). Further, in order to compensate for number of children we divide household disposable income by the square root of one plus the number of children. A discrete choice translog model,

$$
\Psi=\beta_{l} \ln (T-H)+\beta_{l l}(\ln (T-H))^{2}+\beta_{c} \ln (C)+\beta_{c c}(\ln (C))^{2}
$$

is estimated on a sample of households younger than 70 (mean age for couples). Thus, this is a simplified version of model (4) described above and as in this model $\mathrm{T}=4$ and hours $\mathrm{H}$ are divided by 1000 and income $\mathrm{C}$ by 100000 . The estimated parameters are presented in Table 3 .

\section{(Table 3. Estimated parameters of the Social Welfare Function)}

These parameters produce a welfare function increasing in leisure and income. The indifference curves presented in Figure 2, shows that the welfare function is more sensitive for a change in income rather than leisure.

Next section describes how the social welfare function is used in order to identify an optimal tax/benefit design.

\section{Choosing the optimal tax}

In this section we present the use of SWEtaxben for choosing the optimal tax. As a start consider the following steps for a given tax/benefit system:

1. SWEtaxben provides us with a set of optimal (preferred) hours and consumption for each individual in the sample.

2. At these optimal hours and consumption the households social welfare function is evaluated for each of the four choices of inequality aversion discussed above.

Repeat these steps for a large number of alternative tax/benefit systems and the one that produce the highest aggregate welfare is referred to as the optimal tax/benefit system. Of course this is done for each of the four variants of the welfare functions and it cannot be expected that 
these produce the same optimal design. For this reason the results for all four welfare measures have to be presented.

In order to make a comparison meaningful we have to impose budget neutrality. Thus, for most of the reforms suggested, we impose the restriction that they must produce the same central governmental budget. The criteria of budget instead of tax neutrality are important for benefits like child and housing allowances. For instance, if we introduce an increased child allowance this would increase disposable income of all families with children, but this income is not taxed and without budget neutrality would be considered as a free gift. Such a reform would of course result in an increased welfare for the beneficiaries, but not necessarily if the cost is considered. Neutrality is imposed by changing the proportional municipal tax rate. Hence, as an illustration, assume that we evaluate a decrease in the level of the national tax rate. Even after considering the behavioral changes this might result in decreased tax revenue as well as a deficit in the central governmental budget. In this case we increase the municipal tax rate until budget neutrality is achieved and repeats the steps above. If neutrality is still not achieved the process is repeated once more. Since the municipal tax rate correspond to such a large part of the total tax revenue (the tax rate varies over municipalities in 2006 from 28,89 to 34,24 per cent) it typically requires minor changes in order to achieve neutrality. However, even if neutrality is imposed it is nonetheless interesting to record what effect a reform has on the budget and tax revenue and for this reason this will be presented as part of the results. As mentioned neutrality cannot be imposed mechanically and the results of the historical reforms will be presented without neutrality, the same also applies for flat taxes as well as an age dependent tax.

Before a presentation of the different tax and benefit systems that are included in the evaluation it is appropriate to give a short description of historical tax rates as well as of the system in year 2006 (the reference year).

\section{Swedish income taxes a background}

Since the early eighties several tax reforms has been implemented and the main purpose have been to reduce marginal tax rates for average and high income earners, and at the same time maintain a progressive structure as well as tax revenues. Figure 3 shows the dramatic changes in tax rates since 1983. The most important tax reform during this period is the 1991-reform, which can be described by a decrease in income taxes, a broadening of the tax base and an introduction 
of a dual income tax system with a proportional tax on capital (30\%). From 1991 the income tax system has undergone several changes but still kept much of its basic post-reform structure. However, an important change was introduced in 2007, when an in-work tax credit was introduced. The tax credit was reinforced during 2008 and further in 2009 when also the state tax was lowered.

In the beginning of the eighties the Swedish income tax system was known for its high level, large number of brackets and a high degree of progressivity. Today, in 2009 a low or medium income earner pays an income tax similar to an average OECD level (OECD (2007)). The municipal and state taxes, as a share of earnings, have decreased by almost 10 percentage points since 1980. Despite the income tax-cuts, the tax ratio, measured as total taxes in relation to GNP, is still amongst the very highest in the OECD area and of course this implies that other taxes, such as VAT, has increased. However, when comparing tax ratios one should bear in mind that transfer incomes, like pensions and sickness benefits are regarded as taxable incomes in Sweden.

Lower taxes on earnings and a relatively stable tax ratio imply large changes in the tax mix. From an OECD perspective Sweden is more dependent on income taxes and pay roll fees and less of consumption taxes compared to an average OECD country.

Apart from the historical tax systems we also use as a point of reference the tax system in year 2006, see Figure 5. The Swedish income tax system consists of two parts, a flat municipal tax and a progressive national tax regime. The individual is the taxation-unit and income taxes are independent of marital status. The flat municipal tax rate varies across municipalities; the average municipal tax-rate in 2006 was 31.55 percent, the lowest 28.89 and the highest 34.24 . The marginal taxes have an irregular shape up to SEK 320,000, the first break point for national tax. This shape is explained by the phase-in and phase-out of a basic tax deduction. The national tax rate is 20 percent from the first break point up to the second at SEK 470,000 and 25 percent above that. The distribution of gross (taxable) income shows that most individuals face a marginal tax rate close to the municipal tax rate, and about 22 percent reach the first breakpoint for national tax and only about 7 percent pay the highest rate. 


\section{Selection of tax and benefit systems.}

Aaberge and Colombino characterized a piece-wise tax design by a number of parameters and then searched over the parameter space to find an "optimal" income tax Even if this is an efficient way to select amongst different designs an alternative approach is used in this paper. Since we focus on realistic tax systems in the sense that they have actually existed or are politically/economically credible a discretionary approach is used.

Part of the selected tax designs are based on the historical rules from 1983 to 2009. The evaluation includes every single year since 1983 and in order to make the tax systems comparable income levels that define break points has been converted to 2006 years prices using the consumer price index. Of course the effects of real income increases still remains and therefore there is still an impact of "bracket creep", that is, taxes increases over time since more individuals are taxed at higher breakpoints.

Apart from the historical taxes the tax/benefit system in year 2006 is taken as a reference and based on this system the following changes are evaluated:

(1) State tax; changes in levels, breakpoints and highest bracket.

(2) Basic deduction; changes in level.

(3) Basic and in-work tax credit.

In addition to these changes, the evaluation also includes;

(4) Flat tax.

The benefit systems are also included and levels are changed in;

(5) Child- and housing allowance.

Finally two designs inspired by the optimal tax literature are included;

(6) An age dependent tax.

(7) Zero marginal tax rate at the highest income.

Alternative (6) implies a tax that varies over the life cycle, lower at younger age, higher for mid-age and again lower at older age. Hence, we consider age as a proxy for ability. It can be argued that such a simple scheme can be based on a common sense argument and does not requires an underlying theory but as an example of a design that is less intuitive and based on a theoretical justification is alternative (7). Even if the expected effects of this design are small it is nonetheless an example of a system with some interesting properties. Since the tax rate is zero at 
the highest income there is no income above this level that can be taxed, hence this suggest a tax cut without a decrease in tax revenues. This reform can increase hours for individuals with a high productivity (high wage rates) and result in higher revenues from VAT and payroll taxes. In order to impose this design the marginal tax rate is set to zero at an high income and different levels are evaluated; starting at one million SEK and gradually increasing up to ten million.

Next section presents a short summary of the evaluation of each of the tax/benefit design and thereafter the combined effects of the most relevant designs are presented. To give a broader picture and not only focus on the different measures of welfare, also measures of the effects on disposable income, working hours and participation, and tax and budget effects are presented.

\section{Result}

\subsection{Historical taxes}

Figure 6 presents the expected changes on working hours and work participation. For convenience the results are presented as percentage changes since 1983. Three different segments can be identified. First, the period until 1990 where change in hours and participation has been small. Secondly, the dramatic impact of the 1991 year reform, an almost 7 percent increase in working hours in 1991 compared to 1983 and a corresponding increase in participation of almost 3 per cent. Thirdly, the 2007 reform (with the in-work tax credit) has a noticeable effect both on hours and participation. The figure summarizes the impact of decreasing marginal tax rates as well as replacement rates. Note that this does not say anything about the actual change in hours/participation since 1983; instead it presents model predictions based on data from 2006 on a wide range of different tax designs. Already it seems clear that the model reacts toward decreased progressivity; note the change in working hours in 1991 but also towards changed replacement rates, note the change in participation after 2006.

Figure 7 display the effects on household disposable income, earnings and taxes. Note the strong increase in both earnings and disposable income due to the 1991-reform. The stronger increase in disposable income is of course explained by the reduction in income taxes. The reform 2007-2009 has a similar although not such a strong effect. The large decrease in tax rates after 1983 have a large impact on tax revenues and incomes. Comparing 2009 years rules with 
the base alternative in 1983 produce a reduction in tax revenues on labor income of about 35 per cent, at the same time disposable income increase by more than 30 per cent. The 8 per cent increase in earnings is directly related to the increase in working hours presented in Figure 6.

In Figure 8 the four welfare measures are presented, where $\mathrm{W}_{1}$ has the highest inequality aversion and $\mathrm{W}_{4}$ the smallest. Since budget neutrality is not enforced the profile of these welfare measures will be similar to that of disposable income. Disposable income has a major effect on welfare and even if working hours has increased since 1983 this increase is too small to have a sizeable effect. The income effect dominates which of course follows from not enforcing budget neutrality. Thus, our simulations show that 2009 year tax system results in an increase in disposable income of about 30 per cent compared to the system 1983, the corresponding increase in welfare is $15-23$ per cent depending on the inequality weights. The increase in disposable income due to the reforms 1991 and 2007-2009 has a clear welfare effect and the strongest increase is in $\mathrm{W}_{1}$.

The structural reforms 1991 and 2007-09 have a design such that individuals with the lowest welfare gain the most. This reflects that income is more important than leisure; individuals with a low welfare often have low income and low working hours. Since income plays such an important role the big increase in welfare comes from moving from the non-work state to the work state and even if this results in less leisure the increase in income is more important. As mentioned above the participation has increased by 3.5 per cent in 2009 compared to 1983 , and this has benefitted low welfare households. Of course the individuals with the highest welfare are those with high non-labor income and a large amount of leisure but since the social welfare is the sum of all the individuals those with a high welfare and low working hours are relatively unimportant (they are few and in all alternatives except $\mathrm{W}_{4}$ they also get a small weight). Thus labor has a positive effect on social welfare and a policy that increase work incentives increase welfare and an increase in participation implies that welfare increase most for those with the lowest pre-reform welfare.

A critical requirement for these results is that budget neutrality was not imposed and imposing neutrality produce results that are quite different. For instance, the 1991-reform results in a strong decrease in welfare measured by $\mathrm{W}_{1}$, a moderate decrease for $\mathrm{W}_{2}$ and $\mathrm{W}_{3}$ and an increase for $\mathrm{W}_{4}$. In order to achieve neutrality a substantial increase in municipal tax rate is needed and this proportional tax increase has a strong negative effect on low welfare individuals. 
However, it is not realistic to impose budget neutrality on 1991 year tax reform. This reform was deigned to achieve neutrality by increasing other taxes than tax on labor and to increase municipal taxes creates a completely different tax profile than the 1991 design. Our method of obtaining neutrality by increasing the proportional municipal tax rate has a disadvantage if big changes are required since these changes change the original tax profile which produce unintentionally distributional effects.

Next, we present some findings based on modifications of 2006 year tax/benefit system, starting with changes in the national tax.

\subsection{National tax}

Table A1 in the appendix summarizes the results for three changes in national tax; dropping the highest level, reduced levels and increased breakpoints. Thus, we only consider lowering the tax rates and the reason for this is that the results from the historical taxes show that an increase in national taxes does not increase welfare.

As an illustration to the effects of reduced taxes on the different welfare measures consider the first row in Table A1. This row is denoted reform 0 and displays the results for the base year, that is, for the tax/benefit rules in 2006. Since most results are presented as percentage change relative to the base year most of the entries are zero, except the income distribution D9/D2 (decile 9 / decile 2) and the ranking of the welfare measures. Thus, at the base year the ratio D9/D2 was 2.34, i.e. the median income in decile 9 was 2.34 higher than the median income in decile 2 , and welfare according to $\mathrm{W}_{1}$ was the eight highest of all the 41 evaluated combinations. However, the corresponding rank for $\mathrm{W}_{2}$ was only 31 and for $\mathrm{W}_{3}$ and $\mathrm{W}_{4}$ the lowest of all. Thus, the social planners view of inequality aversion matters.

Let's concentrate on the three reforms that have the highest welfare based on the average value across all four measures. These are; number 22 (dropped highest level and increased breakpoint by $25 \%$ ), number 27 (dropped highest level, increased breakpoint by $25 \%$ and reduced level by $25 \%$ ) and number 6 (decreased level and increased breakpoint by $25 \%$ ). Thus, all these changes imply large changes in the national tax rate. How can we explain that these changes results in a high welfare even for $\mathrm{W}_{1}$ ? Reduction in national taxes only lower taxes for median to high income earners with an income above the breakpoint and low income earners have to pay a higher tax rate since the municipal tax rate have to be increased in order to obtain 
neutrality. One important characteristic of high ranked reforms is that they create a small budget deficit but an increase in both working participation and hours. Consider, as an illustration, reform 22 that implies a budget deficit of less than half per cent and an increase in working hours by almost one per cent and in participation by about 0.1 per cent. Thus, the increase in municipal tax rate needed for neutrality is almost negligible and hence implies almost no tax increase for low income earners and as a result the measures of distribution indicate only a small increase in inequality. Thus, most low income earners are unaffected, a few gains since they have started working, households with higher income gains due to the tax cut and in some cases also due to longer working hours (higher income). This shows a Pareto based argument for lowering national tax rates, most households are unaffected and some gain. However, if the budget deficit due to the tax cut is too big than this argument is not longer valid. This is confirmed by the results listed in Table A1, reforms that result in large budget deficits also obtain a low welfare ranking.

It is informative to contrast two reforms and the expected effects on low income earners. Consider 22 mentioned above and 21 which only had a drop in the highest bracket. Dropping the highest national tax level, does not change either the replacement rates or the budget set for many low earner households. Individuals with low hourly wage rates will not reach a taxable income that is affected by a drop in this tax even evaluated at the highest hours. Thus, zero or almost zero change in participation or working hours. As a contrast reform 22 that also involved an increase in the (first) breakpoint has a potential effect on individuals with relative low wages given they work long hours. Even tax reforms that implies tax changes at high taxable income has a possibility of changing working hours for those with lower hourly wages. Same mechanism can of course also be found for individuals with higher wage rates but low labor income (due to short hours). Dropping taxes at high taxable income of course has a larger effect for higher incomes but for these individuals the income effect might dominate and reduce hours.

To continue with reform 22 (dropped highest level and increased breakpoint by $25 \%$ ) which has a high rank on the average over all four welfare measures and based on $\mathrm{W}_{1}$ third place and on $\mathrm{W}_{2}$ it's number one and for $\mathrm{W}_{3}$ and $\mathrm{W}_{4}$ number four. Thus this can be considered an optimal tax, however reform 27 (dropped highest level, increased breakpoint by $25 \%$ and reduced level by $25 \%$ g give same average rank for $\mathrm{W}_{1}-\mathrm{W}_{4}$, but a lower for $\mathrm{W}_{1}$. Also reform 6 
(decreased level and increased breakpoint by $25 \%$ ) and reform 1, (increased breakpoint by 25 \%) has a high rank.

To conclude, an important condition for a high ranked reform is that the budget deficit is not too large. In order to argument for larger tax cuts other criteria than social welfare has to be used. For instance if the criteria is to maximize labor supply, than reform 20, that abolish the national tax should be chosen. However, this alternative has the highest distribution of income as measured by Gini and D9/D2 and as a result the lowest welfare ranking.

\subsection{Basic deduction}

The basic deduction has a low income profile and in contrast to an in-work tax credit allows a reduction of taxable income even for non-labor income. According to Table A2 an increase of this deduction, up to a reasonable level, has a positive effect on low welfare individuals. Based on $\mathrm{W}_{1}$ the optimal level is an increase by 200 per cent (compared to 2006), corresponding results for $\mathrm{W}_{2}$ an increase by 100 per cent, for $\mathrm{W}_{3} 2006$ year system and according to $\mathrm{W}_{4}$ it should be removed completely. This certainly reflects the low income profile, but a too high increase does not increase welfare since neutrality requires a strong compensating increase in municipal tax rates. Thus an increase of the basic deduction can be a component in an optimal tax. Also note that an increased deduction results in reduced replacement rates and increased participation, however, as will be presented below, not to the same extent as an inwork tax credit.

\subsection{In-work tax credit and basic deduction}

Since we follow the design of the in-work tax credit that was introduced in 2007, and extended 2008-09, the tax credit cannot be evaluated independently of the basic deduction. The in-work tax credit is derived from a gross credit and obtained by subtracting the basic deduction. This net-credit is finally multiplied by the municipal tax rate. In order to keep this design intact both the credit and deduction have been changed by the same factor; here an increase from 50 per cent up to 300 per cent.

The results are presented in Tables A3a-A3b. Our results confirm those reported in the literature, see Saez (2002), Immervoll et. al. (2005) and Blundell \& Shephard (2008) for international studies and Aaberge \& Flood (2008) and Flood et. al. (2007) for Sweden. The work 
requirement reduce the replacement rate and hence affect the extensive margin where the supply effects are largest and this produce a large effect on disposable income for low income households and therefore increase social welfare.

An interesting discussion is provided in Immersvoll et. al., where an in-work tax credit is compared to a tax deduction without any working condition. According to their findings the inwork tax credit is preferable and has positive welfare effects for most EU-countries, but an exception is Sweden. An explanation given in the paper is the compressed Swedish wage distribution. This reflects that there is a potential for a greater improvement in welfare increase if there is a larger spread in the prior income distribution. However, it should also be mentioned that Immersvoll et. al. do not evaluate the actual Swedish design. The Swedish design deviates from all other countries since there is no phase-out region, implying that the credit also applies for high income earners. An advantage of the design is the absence of marginal effects caused by a phase-out region, while on the other hand the tax credit is much more costly. Another important difference is that all income earners are eligible and there is no low income target group like lone mothers or families with children. Such a targeted credit would of course reduce the budget deficit dramatically but also the importance of the dynamic effects.

Table A3a shows that participation as well as disposable income and welfare increase with the level of the credit. Since the increase in participation is largest for low income households this is also where the welfare increase is largest. An increase of the deduction by 100 per cent, gives the maximum for $\mathrm{W}_{1}$ and $\mathrm{W}_{2}$, and corresponding results for $\mathrm{W}_{3}$ is 50 per cent and for $\mathrm{W}_{4}$ no increase. To increase the deduction above 100 is not optimal and again this is due to the corresponding increase in municipal taxes. An increase in the range of 50-100 per cent might look unrealistically large, but in relation to the level of EITC ${ }^{9}$ this does not appear to be an unrealistic level.

As mentioned above the Swedish in-work tax credit deviates from the mainstream design due to lack of a phase-out region. In order to evaluate the effect of such a phase-out design, we select a phase-out region that from its maximum value reach zero-level at a taxable income at the upper level for national tax. As follows from Table A3b this produce a lower increase in working hours $(0.92 \%)$ compared to the 2009 -design $(1.57 \%)$ and as expected the effect on participation

\footnotetext{
${ }^{9}$ Earned Income Tax Credit is the in-work tax credit in the US. This profile is quite different from the Swedish but in 2008 the maximum yearly level was $\$ 4824$. Using an OECD PPP-adjusted exchange rate at 9.3, gives a maximum of about 45000 SEK which should be compared to 18000 SEK using the maximum level for 2009.
} 
is only slightly lower. The important result is that the larger dynamic effect of the 2009-design without a phase-out region results in almost the same effect on the governmental budget and hence this is a strong argument for the current Swedish design.

The basic deduction in combination with the in-work tax credit creates tool for finetuning the tax profiles. The in-work tax credit creates incentives to increase income for nonworkers with a potential ability to work and the basic deduction creates possibility to increase income for individuals with a low potential to join the labor force, such as, old old-age pensioner, or disability pensioner with serious health problems. An optimal tax therefore can include both these components although an argument against such a design, on top of municipal and national tax-schemes, is that it produces a complicated system. Further, these deductions are costly in terms of lost tax revenues, according to the budget proposition 2009 the in-work tax credit reduce tax revenues by 65 billion SEK and our own calculation estimate the corresponding cost of the basic deduction to 54 billion SEK. ${ }^{10}$ By comparison, these levels can be compared to the total tax revenue from municipal and national taxes of about 570 billion. This leads to the question what level of a flat tax that is required in order to produce the same tax revenues as the current tax system, this is discussed in next section.

\subsection{Flat tax}

A flat tax has been part of the international tax debate for many years, e.g, Hall \& Rabushka $(1985,1995)$, and it is also a tax that has been implemented or are in the process of being implemented in a number of countries, especially a number of east European so called transitional countries. Although it does not seems to be part of the current debate within the OECD area, instead a progressive system combined with an in-work-tax credit seems to be the norm, see Messere, Kam \& Heady (2006).

Despite the current debate there are a number of arguments in favor of a flat tax, such as simplicity and long run effects on economic growth. Here, simplicity should not be regarded in the myopic sense of just producing simple rules for income taxation, but rather in a general sense. A flat tax on labor income at a rate harmonized with income on capital can result in a

\footnotetext{
${ }^{10}$ Since the in-work tax credit and the basic deduction are related the effect on tax revenues has been calculated conditional on a zero in-work tax credit.
} 
system that reduces the classical challenges caused by different tax rates on capital and labor. This raises an important shortcoming of studies of income taxation; the question of optimal taxation should be generalized to the whole tax system and not only taxation of labor. The whole tax mix should be included in the analyses. However, for obvious reasons this would require an extremely complicated simulation model. Anyway, it is important to realize that a flat tax has several advantages that are not rewarded in this study. The possibility to reduce the incentive to move income to the source with lowest taxation might be the most important but also long run effects on economic growth are not considered in our analysis.

In the evaluation of the flat tax budget neutrality is not imposed. To compensate a change in a (proportional) flat tax by a change in a (proportional) municipal tax is not meaningful; instead the evaluations focus on other dimensions than welfare.

Table A4 shows that a flat rate of 20 per cent produces the highest welfare and 35 per cent the lowest. A 20 per cent flat tax rate has a strong positive effect on working hours and therefore also on disposable income, an increase by more than 17 per cent. Even if labor income increases with almost 5 per cent this is not enough to compensate for reduced taxes (a drop of more than 30 per cent). Of course it is not realistic to suggest a flat rate at 20 per cent, but note that a 30 per cent tax is budget neutral and that at 25 per cent the budget deficit less than 5 per cent.

Since the base case is 2006 , before the in-work tax credit, this deficit would be much smaller if we instead compared with 2009. Using SWEtaxben for this comparison shows that a 25 per cent flat tax is almost budget neutral. This result confirms earlier results, see Lundgren et. al. (2008).

The distributional consequences of a flat tax are presented in Table A4. A tax rate at 25 per cent increase the Gini coefficient by 9 per cent (compared to 2006) and the ratio D9/D2 increases from 2.34 to 2.67. One reason that the income distribution does not increase more is the increase in participation. A low flat tax decrease the replacement rate and increase participation, in difference from an in-work tax credit the flat tax also increase working hours for median and high income earners.

To conclude, a flat tax has several interesting properties but since these are not favored within the optimal taxation framework the disadvantage in terms of increasing income distribution will have a large negative impact in an evaluation. A possible approach could be to 
combine a flat tax with generous benefits targeted at low income households. For this reason next section consider the evaluations of two such benefits.

\subsection{Child and housing allowances}

Child and housing allowances are included due to their importance and also since they have a different income profile; child allowance is given to all families with children while housing allowance is means tested and only granted to low income households. Unlike a change in the level or profile of the tax system it cannot be expected that a change of these benefits, within reasonable limits, would have important behavioral effects, perhaps at most a small income effect. ${ }^{11}$

Tables A5-A7 summarizes the findings. The results regarding the child allowance is clear; dropping the allowance increase welfare and increasing it reduce welfare. By reducing or completely removing the child allowance the municipal tax can be lowered and this benefits all households with or without children. If the welfare measure is based on a welfare function which does not distinguish family types, such as families with children, there is no reason why this allowance should have a positive distributional effect for low income families.

The housing allowance offers an interesting contrast and the low income profile implies that the optimal level is dependent on the welfare measure. According to $\mathrm{W}_{1}$ the optimal level is a doubling of the level in 2006 , for $\mathrm{W}_{2}$ an increase of 75 per cent, for $\mathrm{W}_{3}$ by 50 per cent and based on $\mathrm{W}_{4}$ no change. This effect is in line with expectations, since this allowance is targeted directly at low income households, this is also a reason for not including other low income targeted benefits like social assistance. However, a non-trivial finding is that removal of housing allowance reduces welfare for all measures, including $\mathrm{W}_{4}$. One reason for this is that the welfare reduction for low income earners are so large that it affects the sum of welfare even if all households have the same weight.

Since the effects of housing and child-support are so different it is interesting to study the joint effect, see Table A7. The results show that a reduction in housing allowance cannot be compensated by increasing the allowance for children.

\footnotetext{
${ }^{11}$ However an increased child allowance reduce the replacement rate for families on social assistance, since social assistance is phased out at a faster rate given child allowance.
} 
Finally we turn to the evaluation of two reforms inspired by the literature on optimal taxation; an age-dependent tax and one where the marginal tax is set to zero at highest income.

\subsection{Age-dependent tax}

A basic theme in optimal taxation is that a tax should be related to the ability to pay. It is not income that should be taxed but the ability to earn income. Of course it is difficult to implement a tax based on an unobservable like ability. However the crucial idea is that a tax should be related to an exogenous factor, which does not produce any negative incentives. A stimulating and probably not a completely serious variant of this theme is Mankiw \& Weinzierl (2007), who suggest a tax related to length. Taller individuals should pay more tax. Even if this reflects the idea of taxation according to exogenously factor the problem is that length is not so highly correlated with ability. ${ }^{12}$ As an attempt to catch the basic idea of taxing an exogenous factor we suggest a tax that is age-dependent, thus age is used as a proxy for ability.

An age dependent tax is nothing new, for instance the current Swedish system includes an age component. The in-work tax credit has a special and much more generous level for people older than 65. Further, employers' social security contributions are lower for younger people. Here two alternatives of an age dependent tax are evaluated. First a generalization of the age dependent in-work-tax credit, with a higher level for younger than 25 and older than 61, thus an age dependent in-work-tax credit. Secondly, individuals younger than 26 and older than 65 pay a flat tax of 15 per cent, from 26 year of age the tax increase by a constant up to age 45 and then decrease by the same constant until age 65 . The shape of this profile, in age $26-65$, is thus an inverted V, with the peak at age 45. Constants from one to two per cent per year are used in the phase-in and phase-out regions, where one per cent implies a highest tax rate (at age 45) of 35 per cent and at two per cent 55 per cent. Note, in this evaluation as well as in the flat tax evaluation, the basic deduction, national and municipal taxes are set to zero.

The results are presented in Table A8, where the first row shows the base year 2006, the last row, the generalized age dependent in-work-tax credit and the rows in between different constants for the phase in and out regions. The highest welfare is obtained by a one per cent scaling factor (reform 1), this is expected since this reform produce the largest increase in

\footnotetext{
12 The New York Times April, 21, 2007, comments the article "Some readers can take it as a small, quirky contribution aimed to clarify the literature on optimal income taxation. Others can take it as a broader effort to challenge that entire literature."
} 
disposable income (largest reduction in tax revenues). Note, as for flat taxes, these evaluations do not include budget neutrality. Even if reform (1) results in a large budget deficit, it also has the largest increase in working hours of all reforms evaluated in this study. Working hours increase almost by 4 per cent and participation more than 1 per cent. Obviously this results in a dramatic increase of labor income. Despite these strong dynamic effects there is a large decrease in tax revenues, but (due to dynamic effects) the decrease in the central government's budget is much smaller (6.6\%) due to smaller social expenditures and increased revenues from payrolland VAT taxes. A purely age based tax affect the income distribution and the Gini coefficient increase about 7 per cent. This is an unavoidable consequence of applying the same tax rate for all individuals with the same age. Increasing the phase in and out constant reduce welfare but also increase tax revenues. It is noteworthy that a constant of 1.5 per cent produce a budget deficit of only 2.4 per cent. However, a consequence of increasing the constant is that the income distribution is increased; middle aged low income earners pay a higher tax rate.

Compared to the inverted V tax, the age dependent in-work tax credit (reform 22) performs relatively well. As expected the increase in participation is high but the effect on the intensive margin is not so large. The budget deficit increase about 4 per cent but, as expected, with a less dispersed income distribution. Once again, increased participation reduces the income distribution. Note that, measured by the Gini coefficient, there is a small reduction in the income distribution but not measured by decile 9 in relation to decile 2 . This reflects a change in both tails of the distribution, many older high income earners receives a higher disposable income and also younger low income individuals increase their income.

\subsection{Zero tax on highest income}

As mentioned earlier this reform is inspired by the optimal tax theory and obtained by setting the marginal tax rate to zero at the highest income (according to the theory at highest ability, see Seade (1977)). ${ }^{13}$ This result is sometimes used as an example of how abstract and non-applicable the theory of optimal taxation is. Thus, it is interesting in itself to demonstrate that even this suggestion is possible to implement and evaluate. The intuition behind this result is that a nonzero marginal tax rate distorts the labor supply of the highest-ability person. If this tax rate were changed to zero, the highest-ability person might choose to work more, which increase his

\footnotetext{
${ }^{13}$ The table of the results is not included but is available from the authors upon request.
} 
welfare. However, the tax revenue would not change, because before the tax change, this labor is not provided, and with a zero tax rate, the extra labor supply is not taxed. This argument applies only at the top of the income distribution, because changes in marginal tax rates below this level affect the taxes paid by people with higher incomes. Unfortunately, this result does not give any information about the marginal tax level just below the top of the income distribution.

Admittedly, the implementation of this theory is far from obvious and we choose to evaluate this reform at different "highest incomes", starting at one million SEK and increasing it up to ten million. As expected the effects on labor supply, income or taxes are almost negligible. The largest effect is of course obtained when the upper limit is set to one million SEK, the increase in working hours is $0.08 \%$, disposable income $0.5 \%$ and tax revenues decrease $0.8 \%$.

To conclude, an age dependent tax has some advantages, simplicity and efficiency. It should be repeated, no other tax evaluated in this study produce such a large increase in labor supply as the simple inverted V-tax using a one per cent phase in/phase-out factor. Compared to a flat tax the age dependent offers an interesting alternative. A low tax at the start and at the end of working life creates incentives both for the entry and exit decision. The disadvantage is an increased income distribution that raises the issue of compensation for low income households. This also raises the issue of combination of tax/benefit designs which provides a link to the next section, an evaluation of the optimal combination of tax/benefits.

\subsection{Combined reforms}

A relevant question concerns the combined effect of those reforms discussed above and the purpose of this section is to identify the optimal combination. The tax/benefits that are included in the combined designs are; national tax at the highest level, the level and the breaking point for national tax, basic - and in work tax credit and housing allowances. The in-work tax credit also includes the age dependent design mentioned above. Since a number of variants are possible for each reform this means a total of 80 combinations. The reforms are ranked according to the highest average welfare over all four measures $\mathrm{W}_{1}-\mathrm{W}_{4}$. Table A9 presents the results and as usual the first row presents the basis alternative, i. e. 2006 years' rules.

As expected the welfare ranking is dependent on which measure we use. For instance the reform that gives the highest average welfare gives a relative low welfare for $\mathrm{W}_{1}$. If we still choose this reform it means that the highest national tax is unchanged $(0 \%)$, the level of the 
national tax is reduced (- 25\%), an increase of the breaking point (25\%), an increase of the housing allowance (50\%) and an age dependent in-work tax credit on 2009 years' level. The differences in the reforms that are ranked just below are small. For example the only difference for the reform that is placed second highest is that the highest national tax has been cancelled.

If a more equal welfare distribution is emphasized, the focus is on $\mathrm{W}_{1}$ and $\mathrm{W}_{2}$ and from Table A9 reform 78, ranked on ninth place (of 80), seems to be the optimal choice. This reform is characterized by deleting the highest national tax (-100\%), a reduced national tax level ($25 \%$ ), an increase of the break point (25\%), an increase of the housing allowance (50\%) and a $100 \%$ increase of 2009 years' in-work tax credit and basic deduction. This shows the importance of the deduction/credit for a more even distribution of welfare. For instance if the focus is on $\mathrm{W}_{1}$ then all ten reforms with highest welfare have the doubled deduction/credit. This shows the importance of the basic deduction for decreasing income differences and in-work tax credit for increasing employment. If we continue to study the characteristics of those ten reforms we find that they have the highest increase in working hours at both the extensive and intensive margin and also according to the Gini measure and the D9/D2-ratio a reduction in the income distribution. Furthermore the nine reforms with highest welfare also has a reduction of the national tax, this reduction can take the form of dropped highest tax or reduced levels or increased break point or a combination of these. If the focus is shifted towards $W_{2}$, the main difference concerns the importance of the basic deduction and in-work tax credit. The two highest ranked reforms now has the 100 per cent increase in deduction/credit but then follows reforms that have 2009 years' level with the age dependent credit. Based on $\mathrm{W}_{4}$ as a contrast, the reforms with the highest welfare has a zero increased deduction/credit, but an age depending inwork tax credit. The level on the basic deduction and in-work tax credit has a large importance for the level and distribution of welfare, but when it comes to distributional effects also the housing allowance has an importance. Ranked according to average welfare for $\mathrm{W}_{1}-\mathrm{W}_{4}$ the 12 first reforms has an increased housing allowance (50\%) and according to $\mathrm{W}_{1}$ the 24 first.

The reforms that give the highest welfare reflect changes that are compatible with the theory of an optimal tax design. Lowered national taxes decrease marginal taxes and increases hour of work at the intensive margin, the increase of the in-work tax credit decrease replacement rates and increases work at the extensive margin, increased basic deduction together with 
increased housing allowance decreases the of income distribution. Thus, a textbook illustration off the two crucial factors equity and efficiency.

Our results shows the importance of labor supply, based on average welfare, the highest ranked reforms have large increase in participation and hours. Take as an illustration, reform 78, which has the highest welfare both according to $\mathrm{W}_{1}$ and $\mathrm{W}_{2}$. This reform is associated with an increase in participation of 2.35 per cent and working hours by 3.52 per cent. This is one of the strongest increases of all evaluated alternatives and this leads to an increase in disposable income of almost 15 per cent (highest of all). The reason for these strong dynamic effects is lower national taxes and increased basic deductions and in-work tax credits.

The first row in Table A9 reveals that 2006 tax/benefit rules have the lowest welfare of all evaluated alternatives, thus, compared to 2006 all combinations of tax cuts and benefit increases produce a higher welfare. A natural question is, how does the current (2009) year system rank? This reform is closely described by alternative 11, increased breakpoint ( $25 \%)$, and 2009 year level of the in-work tax credit. This reform is ranked as number 53, and again this show the importance of an increased basic deduction and in-work tax credit, i.e. above the level in 2009. If 2009 years reform is modified with an age dependent in-work tax credit, combination 14 , the ranking increase to 22 and if an increased housing allowance is added, combination 19 , the ranking improves to the fifth place. It should be mentioned that 2009 years reform includes an increased in-work tax credit for older but this is far from what is needed in order to generate a high welfare ranking.

Earlier it has been argued that reforms that reduce tax revenues also tend to reduce welfare due to the need to increase municipal taxes. This mechanism is not longer so obvious for combination of tax/benefits rules. The relatively large initial drop in tax revenues that follows from the reforms that produce high welfare still implies increased municipal tax rates but the negative effects on low income households are now compensated by increased deductions and housing allowances. A reform that initially leads to a drop in tax revenues can be optimal even when it is budget neutral given a profile is such that it is promoting both equity and efficiency. This has relevance for an evaluation of 2009 years reform and a critique against our evaluation is that the 2009 year reform was not designed to be budget neutral. Thus, the reason that the reform 
with a design similar to 2009 reform receives a low rank is that it lacks an increased basic deduction.

An evaluation conditioned on keeping the basic deduction and in-work tax credit at the 2009 years level and vary the other tax/benefits is presented in Table A10. The alternatives with the highest welfare include lower national taxes and higher housing allowances. Note that reform 11 (similar to 2009 design) is ranked on place 11 out of 17. A constructive suggestion to improve on the 2009 years tax/benefit design is to lower the national tax combined with an increase of housing allowance.

Obviously, it is not necessary to base an evaluation only on welfare. Alternatively, participation, working hours or disposable income can be used. These criteria must then be measured before a compensated change in municipal taxes and this also has a degree of realism, for instance if a decrease in taxes on labor are compensated by an increase in taxes on energy. Since labor income measures both the extensive as well as the intensive margin, this forms natural criteria for measuring effects on working hours. Let us summarize the effects on labor supply by changes in labor income. Based on the criteria of maximizing labor income several interesting results follows; basic deduction and in-work tax credit should be increased by 100 per cent, national taxes should be lowered. This also maximizes disposable income but also measured by D9/D2 increases the income spread. An important finding is that high ranked reforms based on the labor income criteria also had a high ranking based $\mathrm{W}_{1}$ and $\mathrm{W}_{2}$. For example, reform 78 which had the highest welfare for $\mathrm{W}_{1}$ and $\mathrm{W}_{2}$ comes at third place ranked by labor income and reform 38 with second highest score based on welfare comes at fourth place based on labor income. Hence, again an illustration that labor is a necessary condition for high welfare. Given this background there seems to be reasons to pick reform 78 as the optimal design. Lower national taxes, increased deductions and credits together with increased housing allowances are balanced to achieve efficiency and equity, to benefit individuals that before the reform had the lowest welfare.

\subsection{Conclusion and summary}

Amongst the large number of tax/benefit designs included in this evaluation a few clear results appear. Tax/benefits compatible with a high social welfare should not produce large marginal 
effects and at the same time not too large differences in welfare. The importance of reduced inequality follows by comparing two benefits like child- and housing allowance. An increase of the housing allowance, with its low income profile, has much more importance for increased welfare compared to an increased child allowance. The importance of reduced marginal effects follows from that decreased national tax is a common feature of the tax designs with highest welfare. Even dropping the highest national tax can be defended based on the welfare argument. The importance of the in-work tax credit deserves to be mentioned for its double merits, reduced replacement rates increase employment which in turn reduce the distribution of welfare.

An increase of both the basic deduction and in-work tax credit increase social welfare. However, these systems also have some important differences in their effects on economic incentives. The basic deduction creates incentives to start working for individuals with zero taxable income and the in-work tax produce incentives to work for individuals with taxable income from other sources except market work. Both types of deduction/credits create income effects for individuals with labor incomes above the maximum levels for these schemes, which might reduce working hours. A too large increase in the basic deduction will have a negative welfare effect, but this negative effect is smaller for an increase in the in-work tax credit since there is also an effect on non-working individuals with a positive taxable income

Even if basic deduction and in-work tax credit in combination with municipal and national taxes creates a possibility of fine tuning the tax profiles we argue that this is not necessarily the path to follow in future tax policy. This analysis certainly stress the importance of a tax policy evaluation based on the welfare criteria but there are also other important criteria. One is simplicity and based on this principle several results in our study are relevant. A 25 per cent flat tax produces approximately the same budget effect as the current 2009 years reform. A flat tax creates new possibilities of harmonization with tax on capital gain and corporate profit. Apart from simplicity a flat tax also produce large dynamic effects but at the same large increases in the income distribution. An age-dependent tax offers an interesting alternative that allows simplicity as well as incentives to early entry and late exit in and out from the working life.

Based on the results in this analysis an optimal tax design with the 2006 years system as a departure, could be formulated as; In order to create incentives for income from work instead of 
benefits and to utilize that increased working hours for high income earners generates large tax revenues an increased basic deduction and in-work tax credit in combination with reduced national taxes is proposed. The social welfare is increased if pensioners as well as individuals on sickness disability and unemployed receive a higher basic deduction. There are no arguments for increasing the child allowance since this is not targeted on low income families. The housing allowances should be increased since it is well targeted at households with low welfare and also comes at a low budgetary expanse. The reform should be financed by a tax increase based on the same tax base as the municipal income tax.

The choice of optimal tax is not independent on the choice of welfare distribution. With this as a background two optimal designs are suggested, and the main difference is the importance of income distribution. A design chosen by a social planner with a strong inequality aversion is reform 78 (see table A9), ranked first measured by $\mathrm{W}_{1}$ and $\mathrm{W}_{2}$, and as number nine measured as the average of all four measures. As an alternative reform 77 is selected, which is ranked as number five based on the average measure. These two reforms differ only with respect to the size of basic deduction and the in-work tax credit. Reform 78 increase the deduction/credit by 100 per cent and reform 77 by 50 per cent. Thus, based on these reforms the main changes compared to the tax system in 2009 , are ;

1. Increased housing allowance by 50 per cent

2. Increased deduction/credit by 50-100 per cent

3. The first breakpoint for national tax is increased to 475000 SEK

4. National tax above first breakpoint is reduced to 15 per cent

5. The highest national tax is dropped

6. A tax increase by about 5-10 per cent based on the same tax base as the municipal tax

Figure 9 compares the marginal tax profiles for the two suggestions with the current 2009 profile. The alternative with a 100 per cent increase in the deduction/credits results in a relatively large increase in marginal tax rates over a large range. This follows from a large increased proportional tax needed to finance the tax cuts but also due to a steeper phase-out of the basic deduction. The increased deductions produce a tax free income up to about 100000 SEK which implies low average taxes for low and median income earners. An increased break point and lower level on national taxes produce lower marginal taxes up to a level slightly below 500000 
SEK, but due to the increase in the compensatory proportional tax, a higher marginal tax for higher incomes.

A natural criticism towards this profile is that most income earners obtain a higher marginal tax compared to the level in 2009. As mentioned above this is caused by the large increase in deduction/credit and for this reason the alternative design with as smaller increase (50 per cent) has an interest. This produce a profile that is much more similar to the 2009 design but compared to 2009 the alternative design benefits low income earners due to a higher tax free income and at the same time high income earners benefits from a lower marginal tax rate. The lower increase in the deduction/credit also benefit median income earner due to a lower compensatory tax increase. The increased lower limit for tax free income gives a lower average tax rate for both low and median incomes.

\section{Concluding comments}

For this kind of evaluation it is important to state the underlying assumptions. This is a study of how the households change income and working hours due to changes in taxes and benefit systems. It is important to realize that the study of behavioral changes is based on a partial approach. We only consider the supply of labor and not the demand. Our analysis assumes a certain degree of adaption and a positive demand for workers. However, at the same time it should be remembered that the estimated parameters that are included in the models for labor supply and participation are affected by the condition on the labor market during the period of estimation. A more balanced view regarding the critic due to absence of a demand side is that we assume a labor market similar to the period of estimation.

The behavioral models included do not produce strong responses due to changed economic incentives. If there are any systematic bias it is more probable that these effects are underestimated. Even if the whole population is included in the evaluation not all individuals in working age are allowed to change working hours, for instance students and older children who are living with their parents. To model mobility between studies and work and the importance of economic incentives in this process is complicated and it is not obvious how to do this in static model. Including older children in the analyses requires household models with more than two adults, and we are not aware of any such study. At the same time it should be mentioned that our 
analyses has an unusually broad coverage, the whole population is included and most individuals in age 16-70 are allowed to change their labor supply. A related problem is that we only consider different working states on a full year basis; disability whole year, unemployed whole year and so on. Thus, a rather large change in the replacement rate is required in order to change between different full time statuses. In principle it is possible to develop a future version of the model that can handle part time status and presumable also students and older children. However, the fact that this is not part of the current model is an argument against overestimation of the impact of economic incentives

The discussion of absence of a demand side of course relates to the current economic crises and rising unemployment (summer 2009). Does this type of analyses have any relevance for the current situation? Probably not if the focus is on short term fiscal policy, but if we look beyond the crisis at the long term effects the design of taxes/benefits systems have a crucial importance. The underlying theme in this type of research is very well summarized in a recent OECD report, "Going for growth" OECD (2009), and the main message, "If the opportunity is seized to make lasting reforms that will improve long-term economic performance, we may look back at this period as one where we repositioned our economies to achieve stronger, cleaner and fairer growth". ${ }^{14}$ The purpose is to develop structural tax systems that create economic incentives, leading to increased labor supply, economic growth and counteract a decreasing old age dependency ratio. This is the idea behind the tax reform started in 2007 and reinforced in 2008 and 2009.

To continue the discussion of assumptions and simplifications in this kind of analysis, the focus on an optimal tax on labor income is a simplification. In reality the whole tax mix should be analyzed. For instance an argument in favor of a flat tax is that it creates possibilities to minimize the problem caused by different tax rates on income from capital, corporate taxes and labor. The administrative costs due to corporate taxation are one reason why OECD considers a reform of corporate taxes as a high priority issue within the OECD area. This is an issue that is not at all considered in this analysis

Another potential critique is the focus on the welfare criteria in evaluation of tax/benefit reforms. An ageing population has increased the awareness of the need for high tax revenues for

\footnotetext{
${ }^{14}$ OECD Secretary Angel Gurría at the presentaion of the report. http://www.oecd.org/document/5/0,3343,en $264934487 \quad 42272581 \quad 1 \quad 1 \quad 1 \quad 1,00 . h t m l$
} 
many years to come. If this problem is taken seriously then the focus should be on reforms that increase labor supply or perhaps maximize tax revenues. A popular illustration of the relation between tax revenue and level of taxation is the Laffer curve. An alternative to this relation is given in Figure 10 where SWEtaxben is used to simulate labor supply for a flat tax from 0 to 100 per cent. As the tax approach 50 per cent the number of working individuals is reduced drastically. At 100 per cent there is still above one million working individuals which could be explained by that there is people working for other than economic reasons. But of course social security is still included. Another reason is that the results at these extreme levels are not trustworthy since this is far outside the estimated parameter space. Thus this Laffer inspired curve should be interpreted with care.

One crucial issue not included explicitly in this paper is the question of short- or long run effects. This is a static analysis and the standard interpretation is that we only consider changes on a market in equilibrium. That is we do not study how individuals adapt to a change but rather after they have adapted, that is in the long run. But another approach to the long run effects would be to study the change over the whole life cycle. A reform can have different effects depending on the age of the individual and these effects can last during many year. A life cycle perspective can give different conclusions regarding an optimal design compared to our static analysis. Take as an illustration an individual who is 25 years old and unemployed. If a reform, such as an in-work tax credit, would lead to that he starts to work there is hence a potential possibility that his life income during 40 year is labor income instead of an alternative and lower benefit. The difference on his living standard measured by disposable income, during his whole life, before as well as after retirement would be large and these differences are enforced by the current pension system which is based on life income. The impact on the central governmental budget is also large. The budget effect for an individual going from full time unemployment to full time market work (in the private sector) in 2006 was about $300000 \mathrm{SEK}^{15}$, thus this should be multiplied by 40 to obtain the accumulated net budget effect. Obviously this is an extreme illustration assuming that an individual is either working or non-working during his active life, but it is also extreme to assume, as we do in this paper, that this effect last only one year. The long run life cycle perspective is certainly relevant facing future challenges in ageing and reduced economic growth.

\footnotetext{
${ }^{15}$ According to calculation in "finanspolitiska rådets" rapport 2008, using a similar simulation model as SWEtaxben.
} 
In a long run perspective reforms that have a large effect on labor supply will have a different assessment compared to our static. A 25 per cent flat tax and a simulated four per cent increase in working hours would at a 20-30 year horizon produce a dramatically higher economic growth compared to the alternative designs that in our analysis produced the highest welfare. To develop a modeling framework to describe the long run effects on life income and taxes and more challenging to describe the effects on income distribution and welfare is an interesting and challenging future research project. 


\section{References}

\section{References}

Aaberge, R. (2000): Characterizations of Lorenz Curves and Income Distributions, Social Choice and Welfare, 17, 639-653.

Aaberge, R. (2001): Axiomatic Characterization of the Gini Coefficient and Lorenz Curve Orderings, Journal of Economic Theory, 101, 115-132.

Aaberge, R., and U. Colombino. (2008). "Designing Optimal Taxes with a Microeconometric Model of Household Labour Supply." CHILD Working Paper no. 06/08.

Aaberge, R, Flood, L.R, 2008 " Evaluation of an In-Work Tax Credit Reform in Sweden: Effects on Labor Supply and Welfare Participation of Single Mothers ", IZA DP No. 3736

Blundell, R., Shephard, A. (2009). "Employment, hours of work and the optimal design of earned income tax credits", IFS Working Papers, W08/0,

Budgetpropositionen för 2009 (2008/09:1)

Edin, P. A. and Fredriksson, P., (2000), "LINDA - Longitudinal Individual DAta for Sweden", Working Paper 2000:19, Uppsala Universitet, Nationalekonomiska institutionen.

Ericson, P, Flood, L.R, Wahlberg, R. (2009). "SWEtaxben: A Swedish Tax/benefit Micro Simulation Model and an Evaluation of a Swedish Tax Reform", Working paper No 346 in SWOPEC, http://swopec.hhs.se/gunwpe/abs/gunwpe0346.htm

Finanspolitiska rådet (2008), "Svensk finanspolitik Finanspolitiska rådets rapport 2008" http://www.finanspolitiskaradet.se/download/18.cd1771b11927f1f0c6800085452/Svensk+finans politik+2008.pdf

Flood, L.R., 2008 "SESIM: A Swedish Micro-Simulation Model", Simulating an Ageing Population A microsimulation approach applied to Sweden. Ed by Anders Klevmarken and Bjorn Lindgren.

Emerald Group Publishing Limited, Howard House UK, pp. 55-83, ISBN 978-0-444-53253-4

Flood, L., J. Hansen, and R. Wahlberg. (2004). "Household Labor Supply and Welfare Participation in Sweden." Journal of Human Resources, 39(4): 1008 -1032.

Flood, L., R. Wahlberg, and E. Pylkänen. (2007).'From Welfare to Work: Evaluating a Proposed Tax and Benefit Reform Targeted at Single Mothers in Sweden." LABOUR, 21(3): 443-471.

Hall \& Rabushka $(1985,1995)$. “The flat tax”, Hoover Institution Press 
Immervoll, H, Henrik Jacobsen Kleven, Claus Thustrup Kreiner, Emmanuel Saez (2005), "Welfare Reform in European Countries:A Microsimulation Analysis," IZA DP No. 1810.

Mankiw \& Weinzierl (2007) The Optimal Taxation of Height: A Case Study of Utilitarian Income Redistribution, Unpublished manuscript, Harvard, 2007

Merz, J., (1991), "Micro-simulation - A survey of principles, developments and applications", International Journal of Forecasting 7pp 77-104

Messere, K., Kam, F and Heady, C., (2006). "Tax Policy Theory and practice in OECD countries", Oxford University Press

Mirlees, J. A. (1971): An Exploration in the Theory of Optimal Income Taxation: Review of EconomicStudies, 38, 175-208. 31

O’Donoghue, C., (2001) "Dynamic microsimulation: A Methodological survey”, Brazilian electronic journal of economics, Vol 4.

OECD (2007) “Taxing Wages 2006-2007 Special feature: Tax reforms and tax burdens”, www.oecd.org/ctp/taxingwages

OECD (2009) "Economic Policy Reforms: Going for Growth", www.oecd.org/economics/goingforgrowth

Owens, J. (2005). “Fundamental Tax Reform: The Experience of OECD Countries,"Background Paper Number 47, Tax Foundation.

Seade, J. (1977). "On the shape of optimal tax schedules", Journal of Public Economics, 7, 203 36

Saez, E. (2001). "Using Elasticities to Derive Optimal Income Tax Rates", Review of Economic Studies, 68, 205-229.

Saez, E. (2002). “ Optimal Income Transfer Programs: Intensive versus Extensive Labour Supply Responses”, Quarterly Journal of Economics, 117, 1039-1073.

Slemrod, J. (1990). "Optimal Taxation and Optimal Tax Systems," Journal of Economic Perspectives, American Economic Association, vol. 4(1), pages 157-78

Stern, N.H, (1976), "On the specification of models of optimal income taxation", Journal of Public Economics, 6, 123-62

Sutherland, H., (1995) "Static Micro-simulations Models in Europe: A survey”, DAE Working Paper No 9523, University of Cambridge. 
Van Soest, A. (1995). "Structural Models of Family Labor Supply." Journal of Human Resources 30(1), 63-88.

Wooldridge, J. (2002). Econometric Analysis of Cross Section and Panel Data, MIT Press.

Wooldridge, J. (2005). "Simple solutions to the initial conditions problem in dynamic, nonlinear panel data models with unobserved heterogeneity." Journal of Applied Econometrics 20, 39 - 54 
Figure 1. Structure of SWEtaxben.

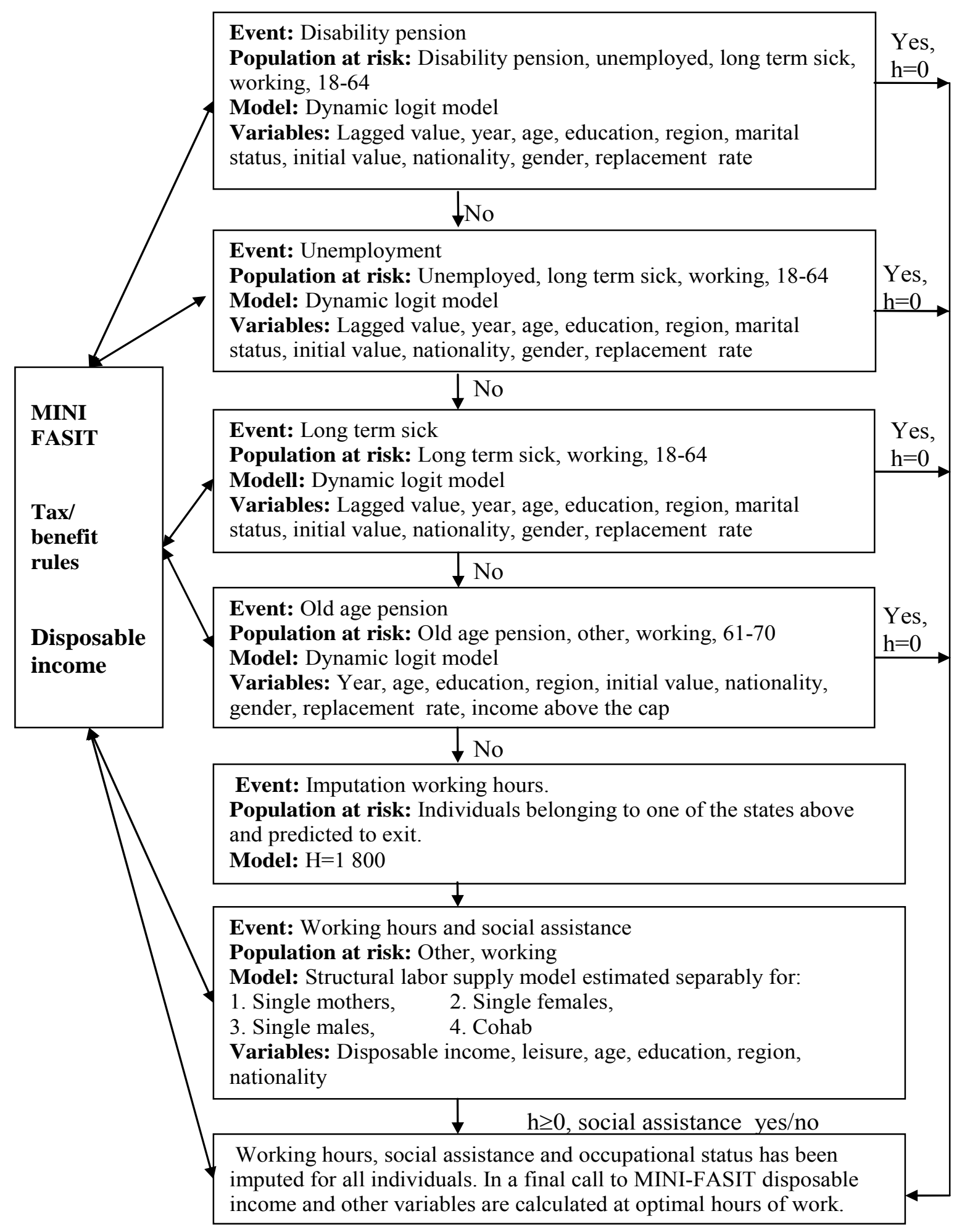


Figure 2. Indifference curves for the Social Welfare Function

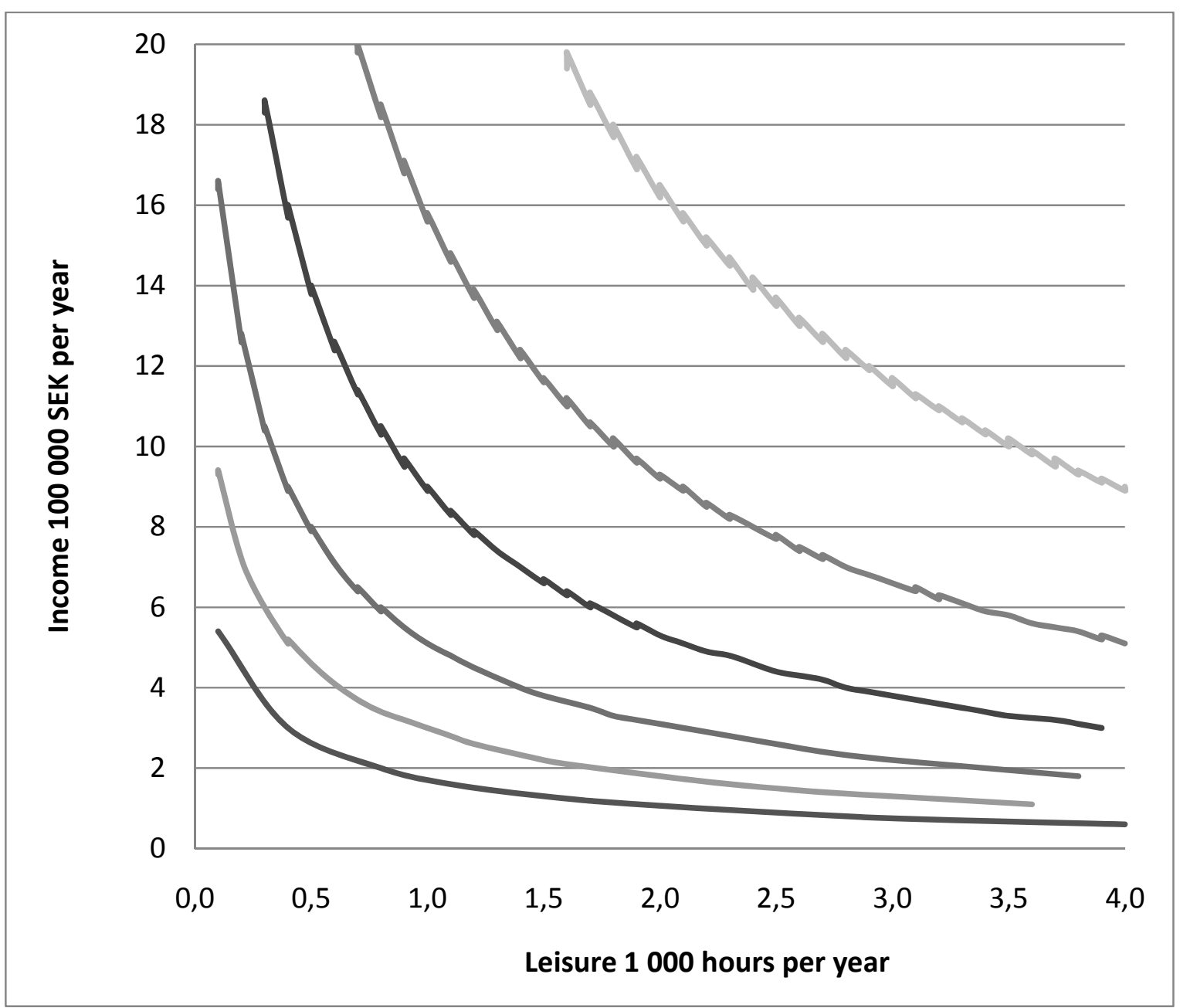


Figure 3. Changes in marginal tax rates 1983-2009

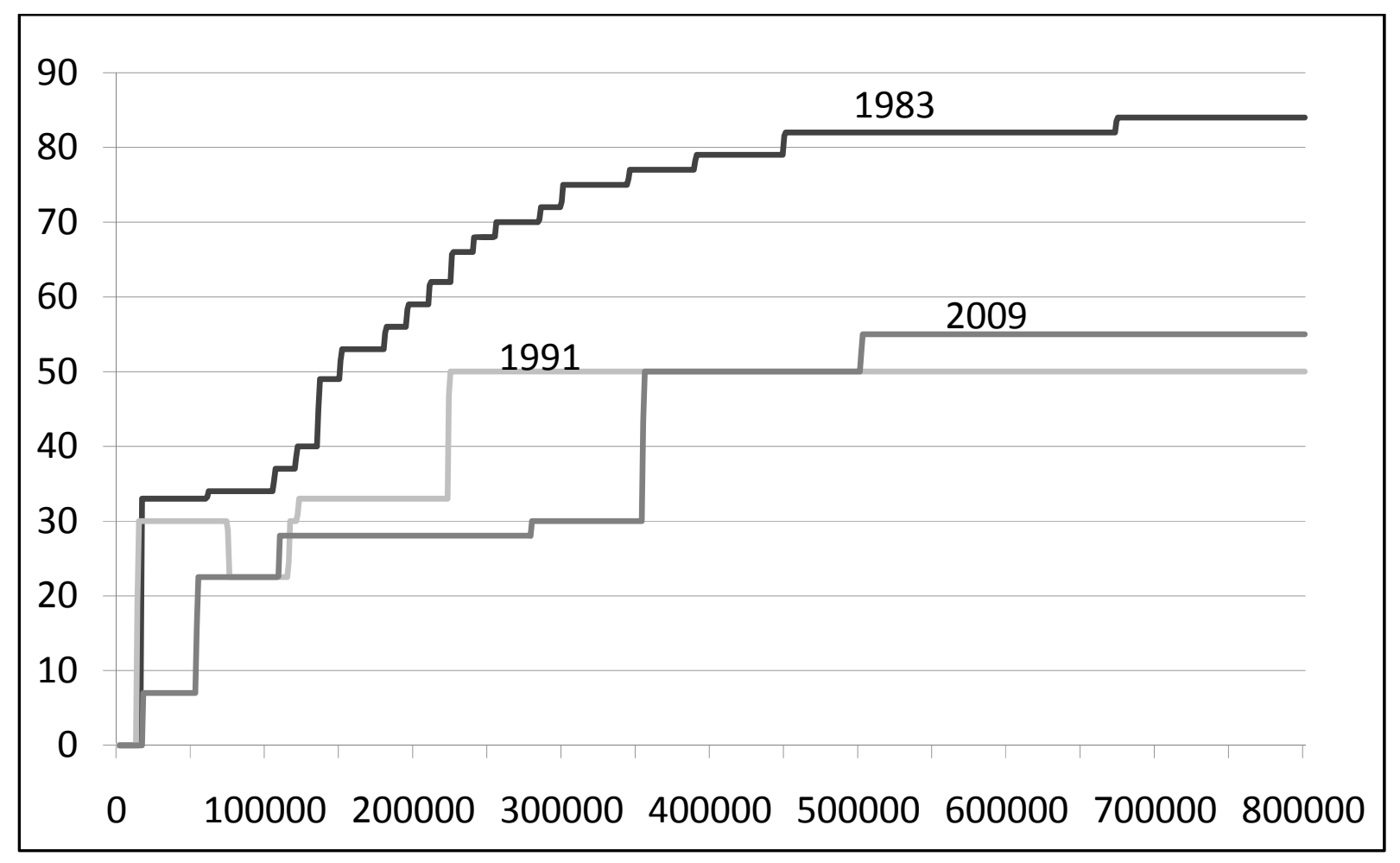


Figure 4. Income tax 2006

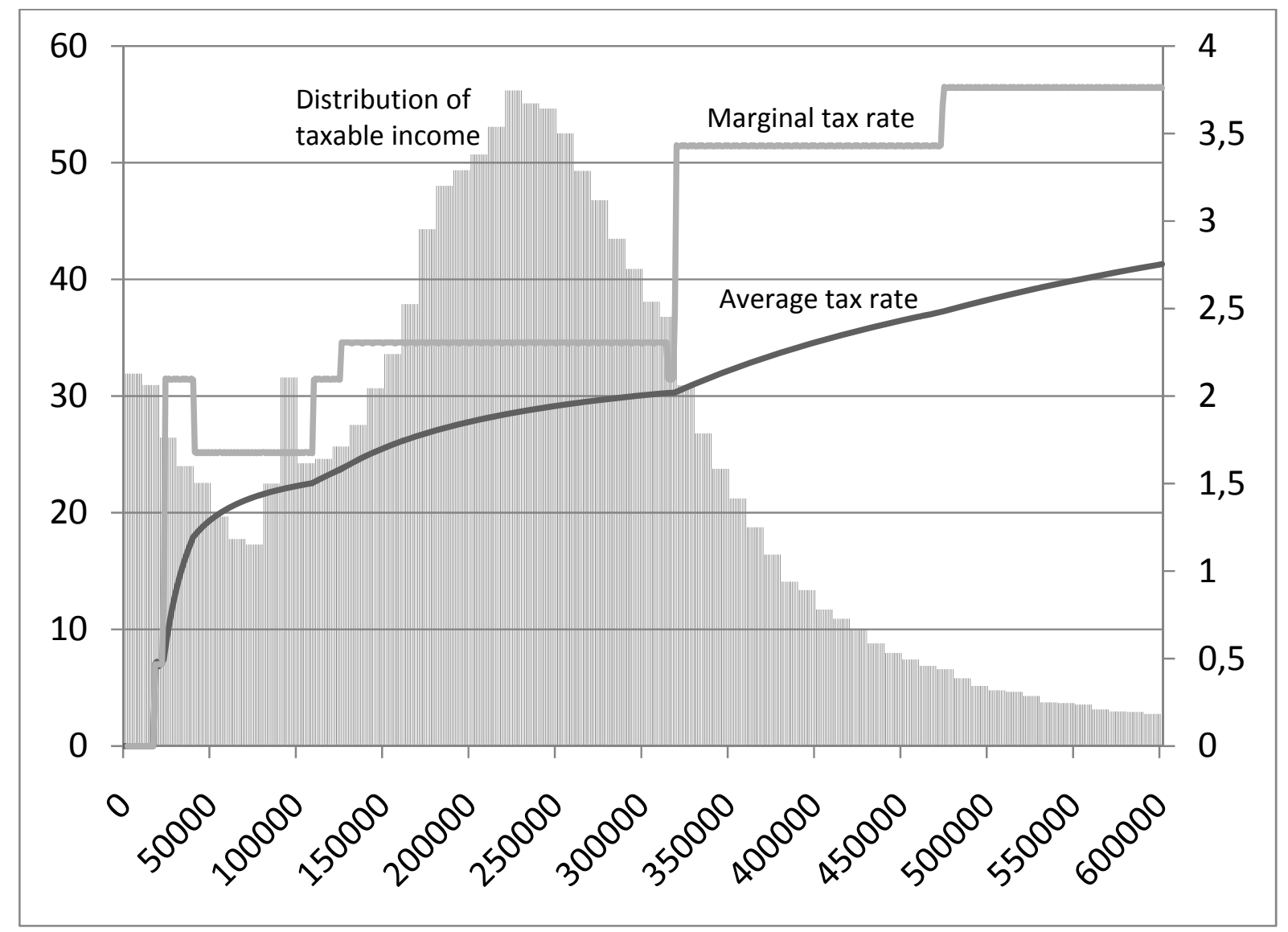


Figure 5. Percentage change in working hours and participation, base year 1983

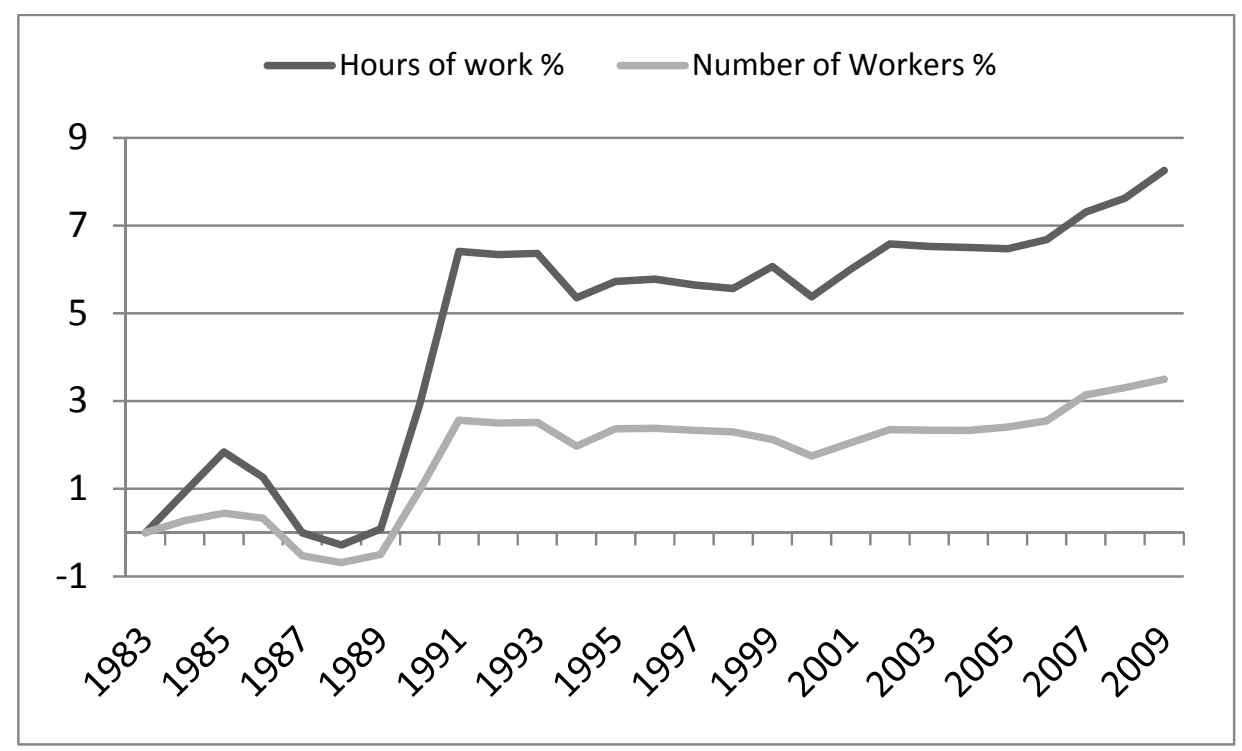

Figur 7. Percentage change in income and taxes, base year 1983.

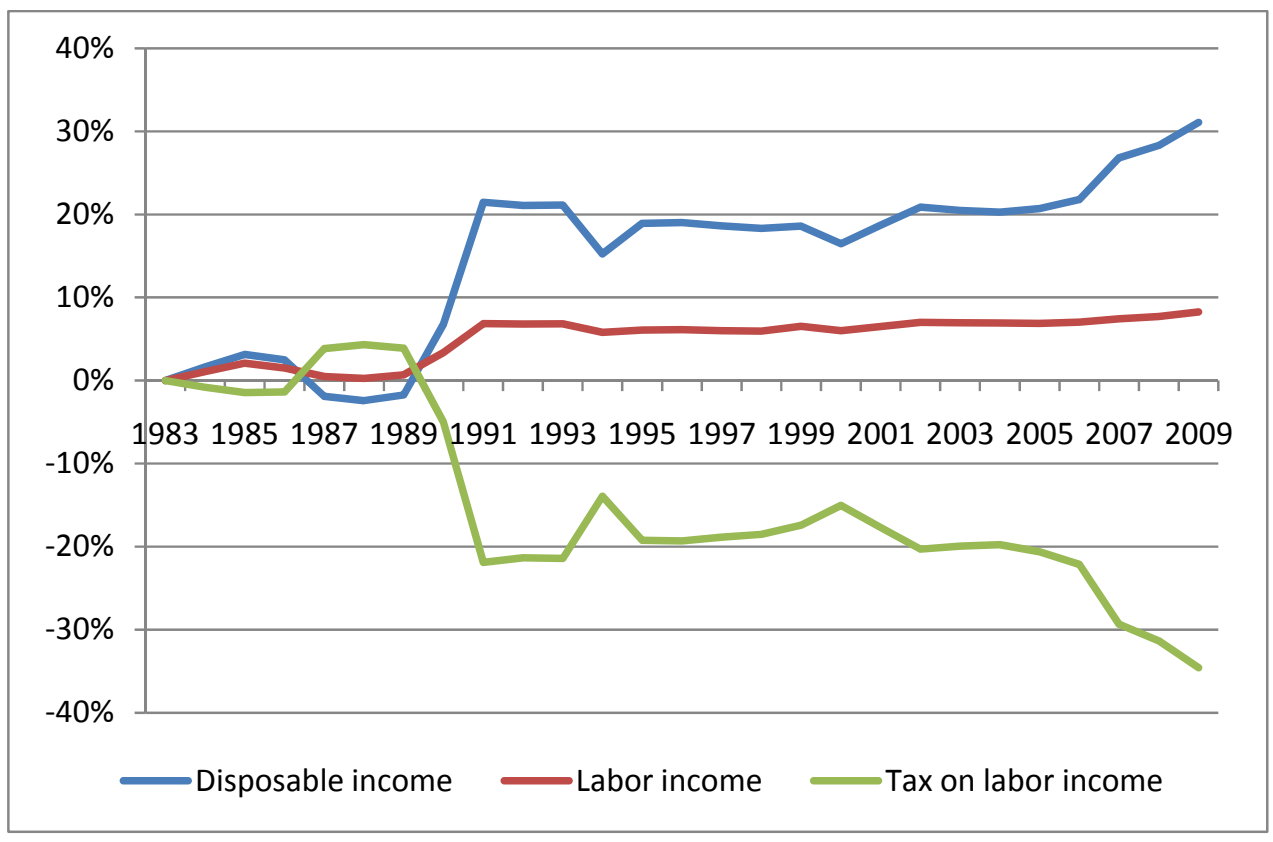


Figure 8. Percentage change in welfare, base year 1983

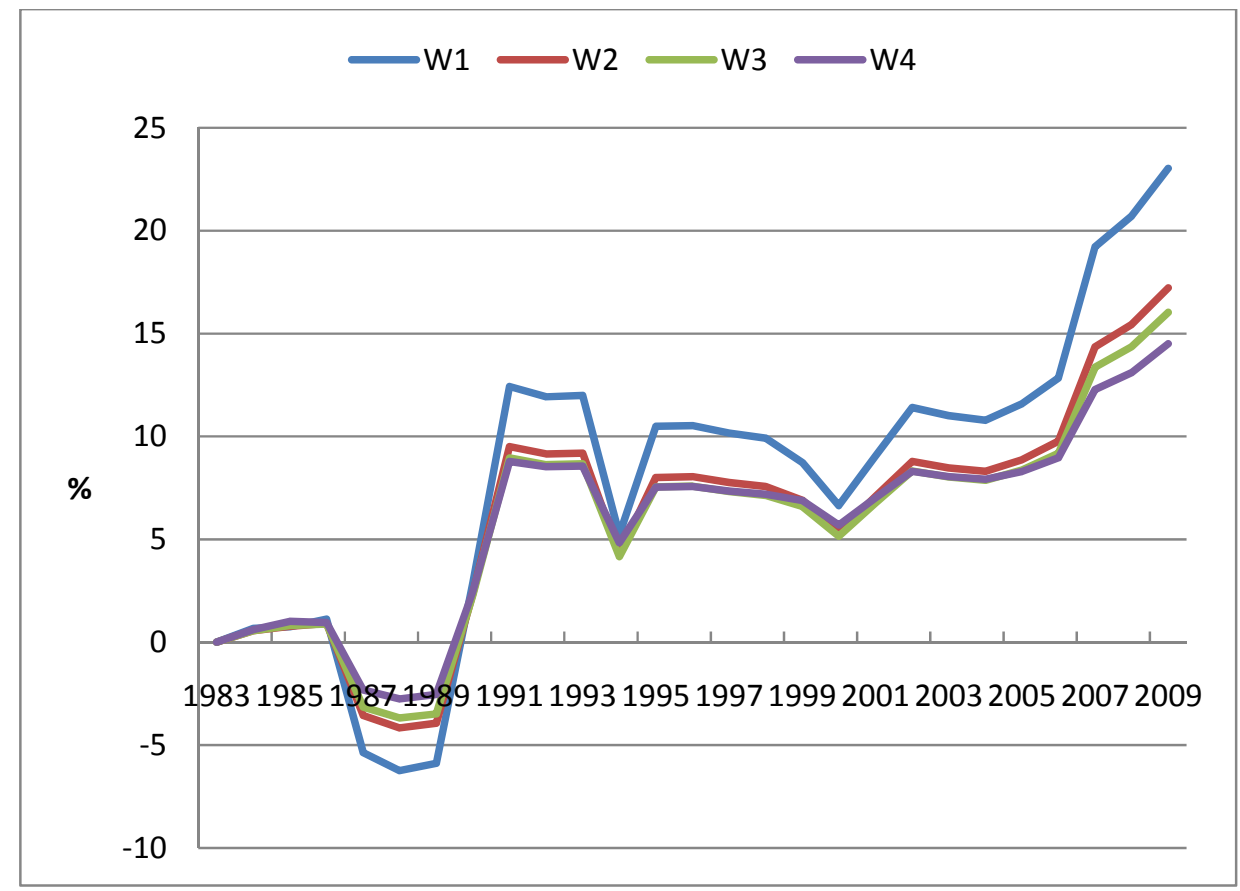

Figure 9. An optimal tax on labor income

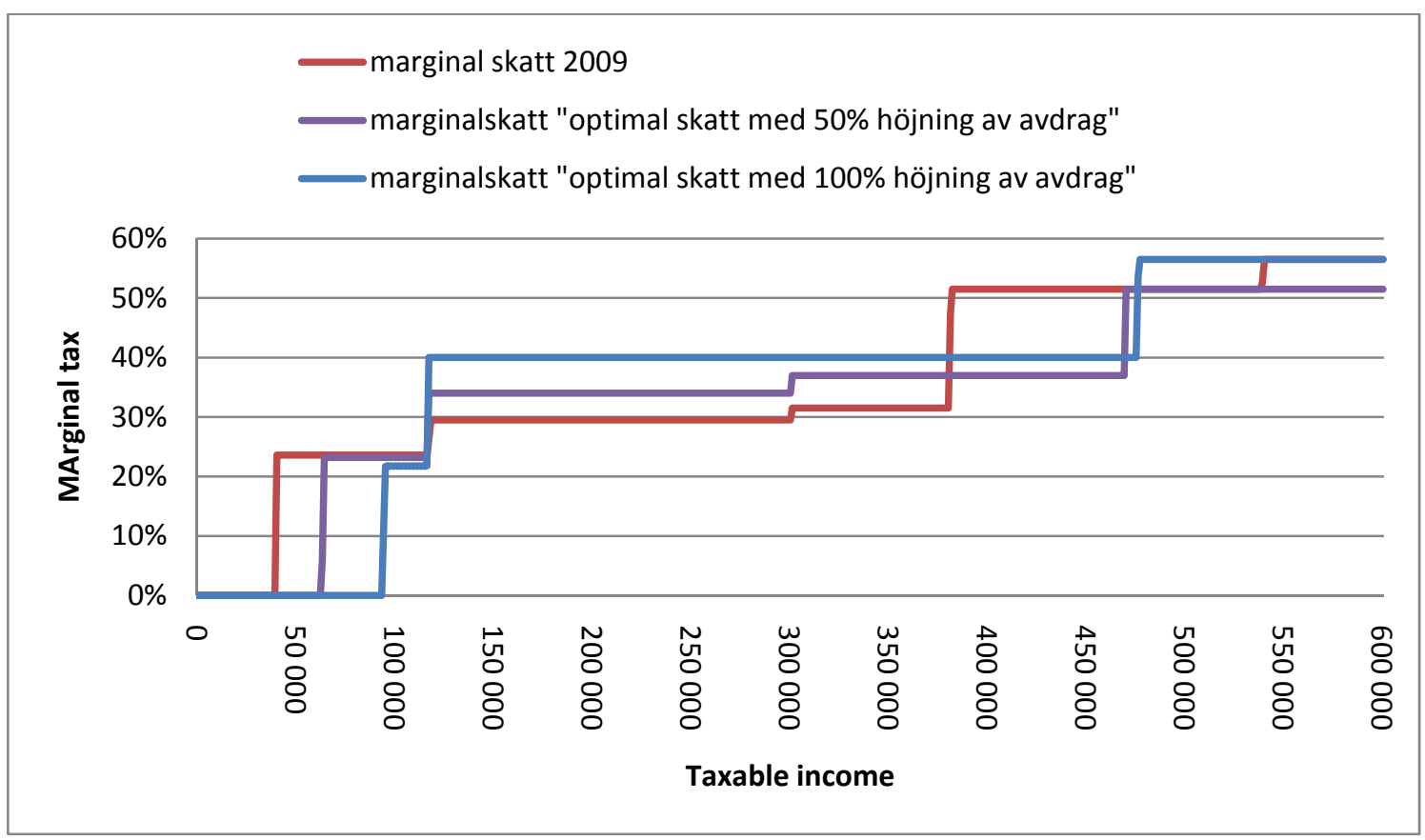


Figure 10. Change in employment and tax levels

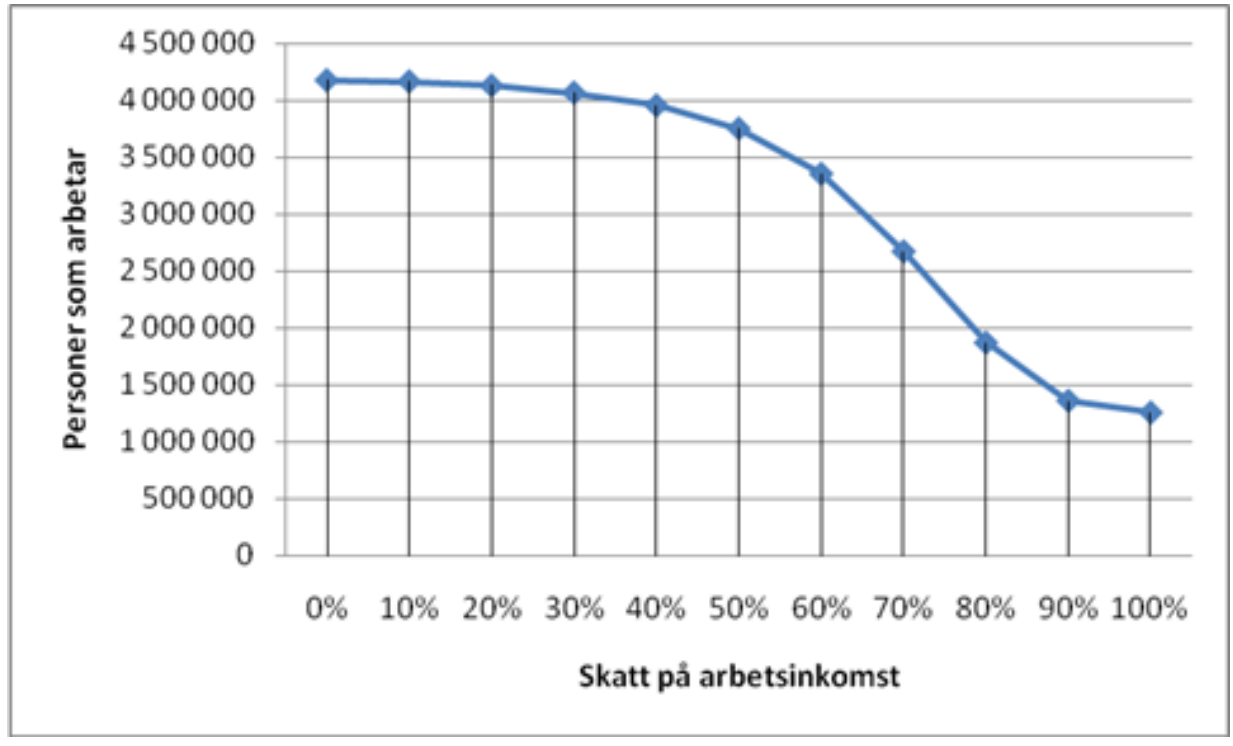


Tables

Table 1. Uncompensated wage elasticities by family type

\begin{tabular}{|l|l|l|l|l|l|}
\hline & \multicolumn{2}{l|l|}{ Household } & $\begin{array}{l}\text { Single } \\
\text { mothers }\end{array}$ & Single & Single \\
\hline Wage increase by 1\% & Male & Female & Female & Female & Male \\
\hline Male & 0.10 & -0.07 & & & 0.05 \\
\hline Female & 0 & 0.16 & 0.21 & 0.38 & \\
\hline
\end{tabular}

Table 2. Distributional weight profiles of four different social welfare functions

\begin{tabular}{|lcccc|}
\hline & $\begin{array}{c}W_{1} \\
\text { (Bonferroni) }\end{array}$ & $\begin{array}{c}W_{2} \\
\text { (Gini) }\end{array}$ & $W_{3}$ & $\begin{array}{c}W_{\infty} \\
\text { (Utilitarian) }\end{array}$ \\
$\mathrm{p}(.01) / \mathrm{p}(.5)$ & 6.64 & 1.98 & 1,33 & 1 \\
$\mathrm{p}(.05) / \mathrm{p}(.5)$ & 4.32 & 1.90 & 1.33 & 1 \\
$\mathrm{p}(.30) / \mathrm{p}(.5)$ & 1.74 & 1.40 & 1.21 & 1 \\
$\mathrm{p}(.95) / \mathrm{p}(.5)$ & 0.07 & 0.10 & 0.13 & 1 \\
\hline
\end{tabular}

Table 3. Estimated parameters of the Social Welfare Function

\begin{tabular}{|l|r|r|}
\hline & Estimates & $\begin{array}{l}\text { Standard } \\
\text { errors }\end{array}$ \\
\hline Log leisure, $\beta_{1}$ & 3.0985 & 0.0215 \\
\hline Log leisure squared, $\beta_{11}$ & 0.3620 & 0.0151 \\
\hline Log income, $\beta_{\mathrm{C}}$ & 4.7262 & 0.0224 \\
\hline Log income squared, $\beta_{\mathrm{CC}}$ & -0.0616 & 0.0089 \\
\hline
\end{tabular}


Appendix I Tables

Tabele A1 National tax

\begin{tabular}{|c|c|c|c|c|c|c|c|c|c|c|c|c|c|c|c|}
\hline Reform & $\begin{array}{c}\text { Top } \\
\text { level }\end{array}$ & Level & $\begin{array}{c}\text { Break } \\
\text { point }\end{array}$ & Hours & $\begin{array}{c}\text { Partici- } \\
\text { pation }\end{array}$ & Budget & $\begin{array}{c}\text { Disposible } \\
\text { income }\end{array}$ & $\begin{array}{c}\text { Labor } \\
\text { income }\end{array}$ & $\begin{array}{c}\begin{array}{c}\text { Income } \\
\text { tax }\end{array} \\
\end{array}$ & GINI & D9/D2 & W1 & W2 & W3 & W4 \\
\hline 0 & $0 \%$ & $0 \%$ & $0 \%$ & $0.00 \%$ & $0.00 \%$ & $0.00 \%$ & $0.00 \%$ & $0.00 \%$ & $0.00 \%$ & $0.0 \%$ & 2.34 & 8 & 31 & 41 & 41 \\
\hline 1 & $0 \%$ & $0 \%$ & $25 \%$ & $0.81 \%$ & $0.08 \%$ & $-0.47 \%$ & $1.76 \%$ & $0.87 \%$ & $-2.30 \%$ & $1.9 \%$ & 2.41 & 2 & 2 & 8 & 8 \\
\hline 2 & $0 \%$ & $0 \%$ & $50 \%$ & $1.18 \%$ & $0.11 \%$ & $-0.69 \%$ & $2.69 \%$ & $1.34 \%$ & $-3.46 \%$ & $3.4 \%$ & 2.44 & 11 & 7 & 7 & 7 \\
\hline 3 & $0 \%$ & $0 \%$ & $75 \%$ & $1.38 \%$ & $0.12 \%$ & $-0.79 \%$ & $3.23 \%$ & $1.63 \%$ & $-4.08 \%$ & $4.6 \%$ & 2.46 & 18 & 12 & 6 & 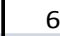 \\
\hline 4 & $0 \%$ & $0 \%$ & $100 \%$ & $1.48 \%$ & $0.12 \%$ & $-0.85 \%$ & $3.55 \%$ & $1.80 \%$ & $-4.45 \%$ & $5.3 \%$ & 2.47 & 21 & 17 & 12 & 12 \\
\hline 5 & $0 \%$ & $-25 \%$ & $0 \%$ & $0.44 \%$ & $0.03 \%$ & $-0.13 \%$ & $1.03 \%$ & $0.60 \%$ & $-1.13 \%$ & $1.9 \%$ & 2.38 & 1 & 5 & 22 & 22 \\
\hline 6 & $0 \%$ & $-25 \%$ & $25 \%$ & $1.02 \%$ & $0.09 \%$ & $-0.54 \%$ & $2.36 \%$ & $1.21 \%$ & $-2.95 \%$ & $3.3 \%$ & 2.42 & 6 & 4 & 3 & 3 \\
\hline 7 & $0 \%$ & $-25 \%$ & $50 \%$ & $1.30 \%$ & $0.11 \%$ & $-0.73 \%$ & $3.07 \%$ & $1.56 \%$ & $-3.85 \%$ & $4.5 \%$ & 2.45 & 14 & 6 & 2 & 2 \\
\hline 8 & $0 \%$ & $-25 \%$ & $75 \%$ & $1.45 \%$ & $0.13 \%$ & $-0.82 \%$ & $3.48 \%$ & $1.78 \%$ & $-4.35 \%$ & $5.3 \%$ & 2.46 & 23 & 18 & 13 & 13 \\
\hline 9 & $0 \%$ & $-25 \%$ & $100 \%$ & $1.52 \%$ & $0.12 \%$ & $-0.88 \%$ & $3.71 \%$ & $1.89 \%$ & $-4.64 \%$ & $5.9 \%$ & 2.47 & 27 & 22 & 17 & 17 \\
\hline 10 & $0 \%$ & $-50 \%$ & $0 \%$ & $0.82 \%$ & $0.06 \%$ & $-0.40 \%$ & $2.05 \%$ & $1.10 \%$ & $-2.45 \%$ & $3.8 \%$ & 2.41 & 9 & 13 & 24 & 24 \\
\hline 11 & $0 \%$ & $-50 \%$ & $25 \%$ & $1.22 \%$ & $0.10 \%$ & $-0.67 \%$ & $2.97 \%$ & $1.53 \%$ & $-3.68 \%$ & $4.7 \%$ & 2.44 & 13 & 9 & 10 & 10 \\
\hline 12 & $0 \%$ & $-50 \%$ & $50 \%$ & $1.41 \%$ & $0.11 \%$ & $-0.81 \%$ & $3.45 \%$ & $1.76 \%$ & $-4.30 \%$ & $5.5 \%$ & 2.46 & 22 & 20 & 18 & 18 \\
\hline 13 & $0 \%$ & $-50 \%$ & $75 \%$ & $1.51 \%$ & $0.12 \%$ & $-0.88 \%$ & $3.73 \%$ & $1.90 \%$ & $-4.65 \%$ & $6.1 \%$ & 2.47 & 29 & 27 & 21 & 21 \\
\hline 14 & $0 \%$ & $-50 \%$ & $100 \%$ & $1.55 \%$ & $2 \%$ & $-0.92 \%$ & $3.88 \%$ & $1.97 \%$ & $-4.85 \%$ & $6.5 \%$ & 2.47 & 34 & 33 & 28 & 28 \\
\hline 15 & $0 \%$ & $-75 \%$ & $0 \%$ & $1.22 \%$ & $0.09 \%$ & $-0.70 \%$ & $3.12 \%$ & $1.61 \%$ & $-3.84 \%$ & $5.7 \%$ & 2.44 & 17 & 25 & 25 & 25 \\
\hline 16 & $0 \%$ & $-75 \%$ & $25 \%$ & $1.42 \%$ & $0.10 \%$ & $-0.85 \%$ & $3.59 \%$ & $1.82 \%$ & $-4.48 \%$ & $6.2 \%$ & 2.46 & 30 & 30 & 29 & 29 \\
\hline 17 & $0 \%$ & $-75 \%$ & $50 \%$ & $1.52 \%$ & $0.11 \%$ & $-0.91 \%$ & $3.84 \%$ & $1.95 \%$ & $-4.80 \%$ & $6.6 \%$ & 2.47 & 33 & 34 & 30 & 30 \\
\hline 18 & $0 \%$ & $-75 \%$ & $75 \%$ & $1.57 \%$ & $0.12 \%$ & $-0.94 \%$ & $3.98 \%$ & $2.03 \%$ & $-4.97 \%$ & $6.9 \%$ & 2.47 & 37 & 37 & 35 & 35 \\
\hline 19 & $0 \%$ & $-75 \%$ & $100 \%$ & $1.59 \%$ & $0.12 \%$ & $-0.97 \%$ & $4.06 \%$ & $2.06 \%$ & $-5.08 \%$ & $7.1 \%$ & 2.47 & 39 & 39 & 37 & 37 \\
\hline 20 & $0 \%$ & $-100 \%$ & $0 \%$ & $1.63 \%$ & $0.12 \%$ & $-1.03 \%$ & $4.24 \%$ & $2.14 \%$ & $-5.32 \%$ & $7.7 \%$ & 2.48 & 41 & 41 & 39 & 39 \\
\hline 21 & $-100 \%$ & $0 \%$ & $0 \%$ & $0.12 \%$ & $0.00 \%$ & $0.00 \%$ & $0.33 \%$ & $0.22 \%$ & $-0.30 \%$ & $0.9 \%$ & 2.48 & 5 & 26 & 40 & 40 \\
\hline 22 & $-100 \%$ & $0 \%$ & $25 \%$ & $0.86 \%$ & $0.08 \%$ & $-0.48 \%$ & $1.94 \%$ & $0.98 \%$ & $-2.47 \%$ & $2.4 \%$ & 2.48 & 3 & 1 & 4 & 4 \\
\hline 23 & $-100 \%$ & $0 \%$ & $50 \%$ & $1.20 \%$ & $0.10 \%$ & $-0.71 \%$ & $2.80 \%$ & $1.39 \%$ & $-3.57 \%$ & $3.8 \%$ & 2.48 & 12 & 8 & 9 & 9 \\
\hline 24 & $-100 \%$ & $0 \%$ & $75 \%$ & $1.39 \%$ & $0.12 \%$ & $-0.80 \%$ & $3.30 \%$ & $1.67 \%$ & $-4.16 \%$ & $4.8 \%$ & 2.48 & 19 & 15 & 11 & 11 \\
\hline 25 & $-100 \%$ & $0 \%$ & $100 \%$ & $1.49 \%$ & $0.12 \%$ & $-0.86 \%$ & $3.60 \%$ & $1.83 \%$ & $-4.51 \%$ & $5.5 \%$ & 2.35 & 25 & 21 & 14 & 14 \\
\hline 26 & $-100 \%$ & $-25 \%$ & $0 \%$ & $0.51 \%$ & $0.03 \%$ & $-0.18 \%$ & $1.28 \%$ & $0.73 \%$ & $-1.41 \%$ & $2.6 \%$ & 2.41 & 4 & 11 & 27 & 27 \\
\hline 27 & $-100 \%$ & $-25 \%$ & $25 \%$ & $1.06 \%$ & $9 \%$ & $-0.56 \%$ & $2.50 \%$ & $1.29 \%$ & $-3.09 \%$ & $3.7 \%$ & 2.44 & 7 & 3 & 1 & 1 \\
\hline 28 & $-100 \%$ & $-25 \%$ & $50 \%$ & $1.32 \%$ & $0.11 \%$ & $-0.74 \%$ & $3.16 \%$ & $1.61 \%$ & $-3.94 \%$ & $4.8 \%$ & 2.46 & 16 & 10 & 5 & 5 \\
\hline 29 & $-100 \%$ & $-25 \%$ & $75 \%$ & $1.46 \%$ & $0.12 \%$ & $-0.83 \%$ & $3.53 \%$ & $1.80 \%$ & $-4.41 \%$ & $5.5 \%$ & 2.47 & 24 & 19 & 15 & 15 \\
\hline 30 & $-100 \%$ & $-25 \%$ & $100 \%$ & $1.52 \%$ & $0.12 \%$ & $-0.89 \%$ & $3.75 \%$ & $1.91 \%$ & $-4.69 \%$ & $6.1 \%$ & 2.38 & 28 & 24 & 19 & 19 \\
\hline 31 & $-100 \%$ & $-50 \%$ & $0 \%$ & $0.88 \%$ & $0.06 \%$ & $-0.43 \%$ & $2.23 \%$ & $1.20 \%$ & $-2.65 \%$ & $4.3 \%$ & 2.43 & 10 & 16 & 26 & 26 \\
\hline 32 & $-100 \%$ & $-50 \%$ & $25 \%$ & $1.24 \%$ & $0.10 \%$ & $-0.70 \%$ & $3.06 \%$ & $1.57 \%$ & $-3.79 \%$ & $5.0 \%$ & 2.45 & 15 & 14 & 16 & 16 \\
\hline 33 & $-100 \%$ & $-50 \%$ & $50 \%$ & $1.42 \%$ & $0.11 \%$ & $-0.82 \%$ & $3.50 \%$ & $1.79 \%$ & $-4.38 \%$ & $5.7 \%$ & 2.46 & 26 & 23 & 20 & 20 \\
\hline 34 & $-100 \%$ & $-50 \%$ & $75 \%$ & $1.51 \%$ & $0.12 \%$ & $-0.89 \%$ & $3.76 \%$ & $1.91 \%$ & $-4.70 \%$ & $6.2 \%$ & 2.47 & 31 & 28 & 23 & 23 \\
\hline 35 & $-100 \%$ & $-50 \%$ & $100 \%$ & $1.55 \%$ & $0.12 \%$ & $-0.93 \%$ & $3.91 \%$ & $1.98 \%$ & $-4.89 \%$ & $6.6 \%$ & 2.41 & 36 & 35 & 33 & 33 \\
\hline 36 & $-100 \%$ & $-75 \%$ & $0 \%$ & $1.24 \%$ & $0.09 \%$ & $-0.72 \%$ & $3.21 \%$ & $1.66 \%$ & $-3.96 \%$ & $6.0 \%$ & 2.44 & 20 & 29 & 31 & 31 \\
\hline 37 & $-100 \%$ & $-75 \%$ & $25 \%$ & $1.43 \%$ & $0.10 \%$ & $-0.86 \%$ & $3.64 \%$ & $1.85 \%$ & $-4.54 \%$ & $6.4 \%$ & 2.46 & 32 & 32 & 32 & 32 \\
\hline 38 & $-100 \%$ & $-75 \%$ & $50 \%$ & $1.52 \%$ & $\%$ & $-0.92 \%$ & $3.87 \%$ & $1.96 \%$ & $-4.83 \%$ & $6.7 \%$ & 2.47 & 35 & 36 & 34 & 34 \\
\hline 39 & $-100 \%$ & $-75 \%$ & /5\% & $1.57 \%$ & $0.12 \%$ & $-0.94 \%$ & $4.00 \%$ & $2.04 \%$ & $-4.99 \%$ & $7.0 \%$ & 2.47 & 38 & 38 & 36 & 36 \\
\hline 40 & $-100 \%$ & $-75 \%$ & $100 \%$ & $1.59 \%$ & $0.12 \%$ & $-0.97 \%$ & $4.07 \%$ & $2.07 \%$ & $-5.10 \%$ & $7.2 \%$ & 2.44 & 40 & 40 & 38 & 38 \\
\hline
\end{tabular}


Table A2 Basic deduction

\begin{tabular}{|c|c|c|c|c|c|c|c|c|c|c|c|c|c|}
\hline Reform & Description & Hours & $\begin{array}{c}\text { Partici- } \\
\text { pation }\end{array}$ & Budget & $\begin{array}{l}\text { Disposible } \\
\text { income }\end{array}$ & $\begin{array}{c}\text { Labor } \\
\text { income }\end{array}$ & $\begin{array}{c}\text { Income } \\
\text { tax }\end{array}$ & GINI & D9/D2 & W1 & W2 & W3 & W4 \\
\hline 0 & Benefit/taxes 2006 & $0.00 \%$ & $0.00 \%$ & $0.00 \%$ & $0.00 \%$ & $0.00 \%$ & $0.00 \%$ & $0.0 \%$ & 2.34 & 3 & 2 & 1 & 2 \\
\hline 1 & No deduction & $-0.05 \%$ & $-0.36 \%$ & $3.38 \%$ & $-3.28 \%$ & $0.02 \%$ & $8.11 \%$ & $2.7 \%$ & 2.43 & 5 & 3 & 3 & 1 \\
\hline 2 & Increase $100 \%$ & $-0.01 \%$ & $0.33 \%$ & $-3.40 \%$ & $3.25 \%$ & $-0.05 \%$ & $-7.96 \%$ & $-2.6 \%$ & 2.27 & 2 & 1 & 2 & 3 \\
\hline 3 & Increase $200 \%$ & $-0.01 \%$ & $0.64 \%$ & $-6.71 \%$ & $6.42 \%$ & $-0.09 \%$ & $-15.63 \%$ & $-4.9 \%$ & 2.19 & 1 & 4 & 4 & 4 \\
\hline 4 & Increase $300 \%$ & $0.05 \%$ & $0.93 \%$ & $-9.54 \%$ & $9.20 \%$ & $-0.08 \%$ & $-22.21 \%$ & $-6.4 \%$ & 2.15 & 4 & 5 & 5 & 5 \\
\hline 5 & Increase $400 \%$ & $0.22 \%$ & $1.16 \%$ & $-11.89 \%$ & $11.61 \%$ & $0.01 \%$ & $-27.80 \%$ & $-7.3 \%$ & 2.15 & 6 & 6 & 6 & 6 \\
\hline 6 & Increase $500 \%$ & $0.52 \%$ & $1.42 \%$ & $-13.76 \%$ & $13.75 \%$ & $0.23 \%$ & $-32.50 \%$ & $-7.7 \%$ & 2.16 & 7 & 7 & 7 & 7 \\
\hline 7 & Increase $600 \%$ & $0.95 \%$ & $1.65 \%$ & $-15.19 \%$ & $15.64 \%$ & $0.56 \%$ & $-36.36 \%$ & $-7.9 \%$ & 2.17 & 8 & 8 & 8 & 8 \\
\hline 8 & Increase $700 \%$ & $1.37 \%$ & $1.85 \%$ & $-16.36 \%$ & $17.27 \%$ & $0.89 \%$ & $-39.65 \%$ & $-7.9 \%$ & 2.19 & 9 & 9 & 9 & 9 \\
\hline 9 & Increase $800 \%$ & $1.73 \%$ & $1.99 \%$ & $-17.37 \%$ & $18.71 \%$ & $1.20 \%$ & $-42.47 \%$ & $-7.7 \%$ & 2.20 & 10 & 10 & 10 & 10 \\
\hline 10 & Increase $900 \%$ & $2.09 \%$ & $2.08 \%$ & $-18.24 \%$ & $20.00 \%$ & $1.50 \%$ & $-44.93 \%$ & $-7.4 \%$ & 2.22 & 11 & 11 & 11 & 12 \\
\hline 11 & Increase $1000 \%$ & $2.46 \%$ & $2.16 \%$ & $-18.97 \%$ & $21.18 \%$ & $1.81 \%$ & $-47.09 \%$ & $-7.0 \%$ & 2.24 & 12 & 12 & 12 & 11 \\
\hline
\end{tabular}


Table A3a In-work tax credit and basic deduction

\begin{tabular}{|c|c|c|c|c|c|c|c|c|c|c|c|c|c|}
\hline Reform & Description & Hours & $\begin{array}{l}\text { Partici- } \\
\text { pation }\end{array}$ & Budget & $\begin{array}{c}\text { Disposible } \\
\text { income }\end{array}$ & $\begin{array}{l}\text { Labor } \\
\text { income }\end{array}$ & $\begin{array}{c}\text { Income } \\
\operatorname{tax}\end{array}$ & GINI & D9/D2 & W1 & W2 & W3 & W4 \\
\hline 0 & Taxes 2006 & $0.00 \%$ & $0.00 \%$ & $0.00 \%$ & $0.00 \%$ & $0.00 \%$ & $0.00 \%$ & $0.0 \%$ & 2.34 & 10 & 10 & 9 & 5 \\
\hline 1 & 2007 in-work taxcredit & $1.05 \%$ & $0.86 \%$ & $-2.24 \%$ & $3.36 \%$ & $0.81 \%$ & $-6.65 \%$ & $-0.8 \%$ & 2.37 & 9 & 7 & 5 & 3 \\
\hline 2 & 2008 in-work taxcredit & $1.38 \%$ & $1.14 \%$ & $-2.98 \%$ & $4.42 \%$ & $1.07 \%$ & $-8.79 \%$ & $-1.0 \%$ & 2.38 & 7 & 5 & 4 & 2 \\
\hline 3 & 2009 in-work taxcredit & $1.61 \%$ & $1.33 \%$ & $-3.69 \%$ & $5.37 \%$ & $1.25 \%$ & $-10.75 \%$ & $-1.2 \%$ & 2.39 & 6 & 4 & 3 & 1 \\
\hline 4 & Increase 2009 credit $50 \%$ & $2.19 \%$ & $1.91 \%$ & $-6.76 \%$ & $8.98 \%$ & $1.68 \%$ & $-18.70 \%$ & $-1.6 \%$ & 2.39 & 4 & 2 & 1 & 4 \\
\hline 5 & Increase 2009 credit $100 \%$ & $2.72 \%$ & $2.36 \%$ & $-9.86 \%$ & $12.56 \%$ & $2.06 \%$ & $-26.57 \%$ & $-1.9 \%$ & 2.40 & 1 & 1 & 2 & 6 \\
\hline 6 & Increase 2009 credit $150 \%$ & $3.28 \%$ & $2.67 \%$ & $-12.75 \%$ & $16.00 \%$ & $2.49 \%$ & $-33.96 \%$ & $-2.2 \%$ & 2.41 & 2 & 3 & 6 & 7 \\
\hline 7 & Increase 2009 credit $200 \%$ & $3.94 \%$ & $2.84 \%$ & $-15.07 \%$ & $19.06 \%$ & $3.03 \%$ & $-40.12 \%$ & $-2.5 \%$ & 2.42 & 3 & 6 & 7 & 8 \\
\hline 8 & Increase 2009 credit $250 \%$ & $4.63 \%$ & $2.88 \%$ & $-16.66 \%$ & $21.50 \%$ & $3.62 \%$ & $-44.54 \%$ & $-2.7 \%$ & 2.44 & 5 & 8 & 8 & 9 \\
\hline 9 & Increase 2009 credit $300 \%$ & $5.18 \%$ & $2.87 \%$ & $-17.70 \%$ & $23.30 \%$ & $4.13 \%$ & $-47.60 \%$ & $-2.8 \%$ & 2.45 & 8 & 9 & 10 & 10 \\
\hline
\end{tabular}

Table A3b Alternativ in-work tax credit with a phase-out region

\begin{tabular}{|c|c|c|c|c|c|c|c|c|c|c|c|c|c|}
\hline Reform & Description & Hours & $\begin{array}{l}\text { Partici- } \\
\text { pation }\end{array}$ & Budget & $\begin{array}{c}\text { Disposible } \\
\text { income }\end{array}$ & $\begin{array}{l}\text { Labor } \\
\text { income }\end{array}$ & $\begin{array}{c}\text { Income } \\
\text { tax }\end{array}$ & GINI & D9/D2 & W1 & W2 & W3 & W4 \\
\hline 0 & Taxes 2006 & $0.00 \%$ & $0.00 \%$ & $0.00 \%$ & $0.00 \%$ & $0.00 \%$ & $0.00 \%$ & $0.0 \%$ & 2.34 & 3 & 3 & 3 & 2 \\
\hline 1 & 2009 in-work taxcredit & $1.57 \%$ & $1.30 \%$ & $-3.54 \%$ & $5.18 \%$ & $1.22 \%$ & $-10.35 \%$ & $-1.2 \%$ & 2.39 & 1 & 1 & 1 & 1 \\
\hline 2 & in-work credit phase-out & $0.92 \%$ & $1.23 \%$ & $-3.35 \%$ & $3.90 \%$ & $0.50 \%$ & $-8.89 \%$ & $-2.6 \%$ & 2.34 & 2 & 2 & 2 & \\
\hline
\end{tabular}


Table A4. Flat tax

\begin{tabular}{|c|c|c|c|c|c|c|c|c|c|c|c|c|c|}
\hline Reform & Description & Hours & $\begin{array}{l}\text { Partici- } \\
\text { pation }\end{array}$ & Budget & $\begin{array}{c}\text { Disposible } \\
\text { income }\end{array}$ & $\begin{array}{c}\text { Labor } \\
\text { income }\end{array}$ & $\begin{array}{c}\text { Income } \\
\text { tax }\end{array}$ & GINI & D9/D2 & W1 & W2 & W3 & W4 \\
\hline 0 & Base 2006 & $0.00 \%$ & $0.00 \%$ & $0.00 \%$ & $0.00 \%$ & $0.00 \%$ & $0.00 \%$ & $0.0 \%$ & 2.34 & 10 & 11 & 11 & 12 \\
\hline 1 & $20 \%$ & $4.78 \%$ & $1.55 \%$ & $-10.28 \%$ & $17.35 \%$ & $4.88 \%$ & $-30.93 \%$ & $8.2 \%$ & 2.84 & 1 & 1 & 1 & 1 \\
\hline 2 & $21 \%$ & $4.60 \%$ & $1.44 \%$ & $-9.13 \%$ & $15.99 \%$ & $4.72 \%$ & $-27.99 \%$ & $8.3 \%$ & 2.81 & 2 & 2 & 2 & 2 \\
\hline 3 & $22 \%$ & $4.41 \%$ & $1.34 \%$ & $-7.98 \%$ & $14.62 \%$ & $4.55 \%$ & $-25.07 \%$ & $8.5 \%$ & 2.77 & 3 & 3 & 3 & 3 \\
\hline 4 & $23 \%$ & $4.18 \%$ & $1.21 \%$ & $-6.86 \%$ & $13.23 \%$ & $4.36 \%$ & $-22.16 \%$ & $8.6 \%$ & 2.74 & 4 & 4 & 4 & 4 \\
\hline 5 & $24 \%$ & $3.95 \%$ & $1.09 \%$ & $-5.75 \%$ & $11.86 \%$ & $4.16 \%$ & $-19.26 \%$ & $8.8 \%$ & 2.70 & 5 & 5 & 5 & 5 \\
\hline 6 & $25 \%$ & $3.69 \%$ & $0.95 \%$ & $-4.66 \%$ & $10.47 \%$ & $3.95 \%$ & $-16.39 \%$ & $9.0 \%$ & 2.67 & 6 & 6 & 6 & 6 \\
\hline 7 & $26 \%$ & $3.43 \%$ & $0.82 \%$ & $-3.57 \%$ & $9.09 \%$ & $3.73 \%$ & $-13.52 \%$ & $9.2 \%$ & 2.63 & 7 & 7 & 7 & 7 \\
\hline 8 & $27 \%$ & $3.18 \%$ & $0.67 \%$ & $-2.50 \%$ & $7.71 \%$ & $3.51 \%$ & $-10.67 \%$ & $9.4 \%$ & 2.60 & 8 & 8 & 8 & 8 \\
\hline 9 & $28 \%$ & $2.89 \%$ & $0.50 \%$ & $-1.44 \%$ & $6.32 \%$ & $3.27 \%$ & $-7.83 \%$ & $9.7 \%$ & 2.57 & 9 & 9 & 9 & 9 \\
\hline 10 & $29 \%$ & $2.61 \%$ & $0.32 \%$ & $-0.40 \%$ & $4.95 \%$ & $3.04 \%$ & $-5.01 \%$ & $9.9 \%$ & 2.53 & 11 & 10 & 10 & 10 \\
\hline 11 & $30 \%$ & $2.29 \%$ & $0.12 \%$ & $0.61 \%$ & $3.56 \%$ & $2.77 \%$ & $-2.21 \%$ & $10.1 \%$ & 2.50 & 12 & 12 & 12 & 11 \\
\hline 12 & $31 \%$ & $1.98 \%$ & $-0.08 \%$ & $1.64 \%$ & $2.18 \%$ & $2.51 \%$ & $0.58 \%$ & $10.4 \%$ & 2.46 & 13 & 13 & 13 & 13 \\
\hline 13 & $32 \%$ & $1.67 \%$ & $-0.27 \%$ & $2.64 \%$ & $0.80 \%$ & $2.24 \%$ & $3.35 \%$ & $10.6 \%$ & 2.43 & 14 & 14 & 14 & 14 \\
\hline 14 & $33 \%$ & $1.32 \%$ & $-0.49 \%$ & $3.61 \%$ & $-0.56 \%$ & $1.96 \%$ & $6.11 \%$ & $10.9 \%$ & 2.40 & 15 & 15 & 15 & 15 \\
\hline 15 & $34 \%$ & $0.95 \%$ & $-0.73 \%$ & $4.55 \%$ & $-1.94 \%$ & $1.65 \%$ & $8.83 \%$ & $11.2 \%$ & 2.36 & 16 & 16 & 16 & 16 \\
\hline 16 & $35 \%$ & $0.60 \%$ & $-0.95 \%$ & $5.52 \%$ & $-3.30 \%$ & $1.38 \%$ & $11.56 \%$ & $11.4 \%$ & 2.33 & 17 & 17 & 17 & 17 \\
\hline
\end{tabular}


Table A5. Child allowance

\begin{tabular}{|c|c|c|c|c|c|c|c|c|c|c|c|c|c|}
\hline Reform & Description & Hours & $\begin{array}{l}\text { Partici- } \\
\text { pation }\end{array}$ & Budget & \begin{tabular}{|c|} 
Disposible \\
income
\end{tabular} & $\begin{array}{c}\text { Labor } \\
\text { income }\end{array}$ & $\begin{array}{c}\text { Income } \\
\text { tax }\end{array}$ & GINI & D9/D2 & W1 & W2 & W3 & W4 \\
\hline 0 & Base 2006 & $0.00 \%$ & $0.00 \%$ & $0.00 \%$ & $0.00 \%$ & $0.00 \%$ & $0.00 \%$ & $0.0 \%$ & 2.34 & 3 & 3 & 3 & 3 \\
\hline 1 & No allowance & $0.07 \%$ & $-0.04 \%$ & $1.62 \%$ & $-1.45 \%$ & $0.08 \%$ & $0.08 \%$ & $3.3 \%$ & 2.42 & 1 & 1 & 1 & 1 \\
\hline 2 & reduced $50 \%$ & $0.05 \%$ & $0.00 \%$ & $0.83 \%$ & $-0.72 \%$ & $0.05 \%$ & $0.04 \%$ & $1.6 \%$ & 2.38 & 2 & 2 & 2 & 2 \\
\hline 3 & Increased $50 \%$ & $-0.07 \%$ & $-0.02 \%$ & $-0.85 \%$ & $0.73 \%$ & $-0.07 \%$ & $-0.06 \%$ & $-1.5 \%$ & 2.32 & 4 & 4 & 4 & 4 \\
\hline 4 & Increasd $100 \%$ & $-0.16 \%$ & $-0.07 \%$ & $-1.74 \%$ & $1.46 \%$ & $-0.16 \%$ & $-0.13 \%$ & $-2.8 \%$ & 2.30 & 5 & 5 & 5 & 5 \\
\hline 5 & Increasd $150 \%$ & $-0.26 \%$ & $-0.12 \%$ & $-2.65 \%$ & $2.19 \%$ & $-0.26 \%$ & $-0.21 \%$ & $-4.1 \%$ & 2.28 & 6 & 6 & 6 & 6 \\
\hline 6 & Increasd $200 \%$ & $-0.36 \%$ & $-0.18 \%$ & $-3.55 \%$ & $2.93 \%$ & $-0.35 \%$ & $-0.28 \%$ & $-5.3 \%$ & 2.26 & 7 & 7 & 7 & 7 \\
\hline 7 & Increasd $250 \%$ & $-0.48 \%$ & $-0.25 \%$ & $-4.48 \%$ & $3.66 \%$ & $-0.46 \%$ & $-0.37 \%$ & $-6.3 \%$ & 2.24 & 8 & 8 & 8 & 8 \\
\hline 8 & Increasd $300 \%$ & $-0.62 \%$ & $-0.34 \%$ & $-5.42 \%$ & $4.40 \%$ & $-0.58 \%$ & $-0.46 \%$ & $-7.1 \%$ & 2.23 & 9 & 9 & 9 & 9 \\
\hline 9 & Increasd $450 \%$ & $-0.75 \%$ & $-0.42 \%$ & $-6.36 \%$ & $5.14 \%$ & $-0.70 \%$ & $-0.54 \%$ & $-7.9 \%$ & 2.23 & 10 & 10 & 10 & 10 \\
\hline 10 & Increasd $500 \%$ & $-0.87 \%$ & $-0.50 \%$ & $-7.29 \%$ & $5.88 \%$ & $-0.80 \%$ & $-0.62 \%$ & $-8.6 \%$ & 2.23 & 11 & 11 & 11 & 11 \\
\hline
\end{tabular}

Table A6 Housing allowance

\begin{tabular}{|c|c|c|c|c|c|c|c|c|c|c|c|c|c|}
\hline Reform & escription & Hours & $\begin{array}{l}\begin{array}{c}\text { Partici- } \\
\text { pation }\end{array} \\
\end{array}$ & Budget & \begin{tabular}{|c|}
$\begin{array}{c}\text { Disposible } \\
\text { income }\end{array}$ \\
\end{tabular} & $\begin{array}{c}\text { Labor } \\
\text { income }\end{array}$ & \begin{tabular}{|c|}
$\begin{array}{c}\text { Income } \\
\text { tax }\end{array}$ \\
\end{tabular} & GINI & D9/D2 & w1 & W2 & W3 & W4 \\
\hline 0 & Base 2006 & $0.00 \%$ & $0.00 \%$ & $0.00 \%$ & $0.00 \%$ & $0.00 \%$ & $0.00 \%$ & $0.0 \%$ & 2.34 & 5 & 5 & 4 & 1 \\
\hline 1 & Reduction $100 \%$ & $0.16 \%$ & $0.11 \%$ & $0.28 \%$ & $-0.09 \%$ & $0.12 \%$ & $0.08 \%$ & $0.3 \%$ & 2.35 & 9 & 9 & 9 & 7 \\
\hline 2 & Reduction $75 \%$ & $0.14 \%$ & $0.10 \%$ & $0.22 \%$ & $-0.06 \%$ & $0.10 \%$ & $0.07 \%$ & $0.2 \%$ & 2.35 & 8 & 8 & 8 & 3 \\
\hline 3 & Reduction $50 \%$ & $0.09 \%$ & $0.06 \%$ & $0.15 \%$ & $-0.05 \%$ & $0.07 \%$ & $0.04 \%$ & $0.1 \%$ & 2.35 & 7 & 7 & 7 & 4 \\
\hline 4 & Reduction $25 \%$ & $0.05 \%$ & $0.03 \%$ & $0.08 \%$ & $-0.02 \%$ & $0.04 \%$ & $0.02 \%$ & $0.0 \%$ & 2.35 & 6 & 6 & 6 & 6 \\
\hline 5 & Increase $25 \%$ & $-0.08 \%$ & $-0.07 \%$ & $-0.12 \%$ & $0.01 \%$ & $-0.07 \%$ & $-0.05 \%$ & $0.0 \%$ & 2.34 & 4 & 4 & 2 & 2 \\
\hline 6 & Increase $50 \%$ & $-0.20 \%$ & $-0.16 \%$ & $-0.25 \%$ & $0.01 \%$ & $-0.16 \%$ & $-0.11 \%$ & $0.0 \%$ & 2.34 & 3 & 2 & 1 & 5 \\
\hline 7 & Increase $75 \%$ & $-0.31 \%$ & $-0.26 \%$ & $-0.40 \%$ & $0.01 \%$ & $-0.25 \%$ & $-0.17 \%$ & $0.0 \%$ & 2.34 & 2 & 1 & 3 & 8 \\
\hline 8 & Increase $100 \%$ & $-0.49 \%$ & $-0.42 \%$ & $-0.60 \%$ & $0.00 \%$ & $-0.39 \%$ & $-0.26 \%$ & $0.1 \%$ & 2.34 & 1 & 3 & 5 & 9 \\
\hline
\end{tabular}

Table A7. Child- and housing allowance

\begin{tabular}{|c|c|c|c|c|c|c|c|c|c|c|c|c|c|c|}
\hline Reform & Child allowance & Housing allowance & Hours & $\begin{array}{c}\text { Partici- } \\
\text { pation }\end{array}$ & Budget & $\begin{array}{c}\text { Disposible } \\
\text { income }\end{array}$ & $\begin{array}{c}\text { Labor } \\
\text { income }\end{array}$ & $\begin{array}{c}\text { Income } \\
\text { tax }\end{array}$ & GINI & D9/D2 & W1 & W2 & W3 & W4 \\
\hline 0 & Base 2006 & Base 2006 & $0.00 \%$ & $0.00 \%$ & $0.00 \%$ & $0.00 \%$ & $0.00 \%$ & $0.00 \%$ & $0.0 \%$ & 2.34 & 1 & 1 & 1 & 1 \\
\hline 1 & Base 2006 & Reduction $100 \%$ & $0.16 \%$ & $0.11 \%$ & $0.28 \%$ & $-0.09 \%$ & $0.16 \%$ & $0.08 \%$ & $0.3 \%$ & 2.35 & 3 & 2 & 2 & 2 \\
\hline 2 & Increase $100 \%$ & Base 2006 & $-0.16 \%$ & $-0.07 \%$ & $-1.74 \%$ & $1.46 \%$ & $-0.16 \%$ & $-0.13 \%$ & $-2.8 \%$ & 2.30 & 2 & 3 & 3 & 4 \\
\hline 3 & Increase $100 \%$ & Reduction $100 \%$ & $0.04 \%$ & $0.09 \%$ & $-1.45 \%$ & $1.40 \%$ & $0.04 \%$ & $-0.03 \%$ & $-2.7 \%$ & 2.30 & 4 & 4 & 4 & 3 \\
\hline 4 & Increase $200 \%$ & Base 2006 & $-0.36 \%$ & $-0.18 \%$ & $-3.55 \%$ & $2.93 \%$ & $-0.36 \%$ & $-0.28 \%$ & $-5.3 \%$ & 2.26 & 5 & 5 & 6 & 6 \\
\hline 5 & Increase $200 \%$ & Reduction $100 \%$ & $-0.16 \%$ & $0.00 \%$ & $-3.27 \%$ & $2.89 \%$ & $-0.16 \%$ & $-0.18 \%$ & $-5.2 \%$ & 2.26 & 6 & 6 & 5 & 5 \\
\hline 6 & Increase $300 \%$ & Base 2006 & $-0.62 \%$ & $-0.34 \%$ & $-5.42 \%$ & $4.40 \%$ & $-0.62 \%$ & $-0.46 \%$ & $-7.1 \%$ & 2.23 & 7 & 7 & 8 & 8 \\
\hline 7 & Increase $300 \%$ & Reduction $100 \%$ & $-0.41 \%$ & $-0.15 \%$ & $-5.14 \%$ & $4.37 \%$ & $-0.41 \%$ & $-0.35 \%$ & $-7.2 \%$ & 2.23 & 8 & 8 & 7 & 7 \\
\hline
\end{tabular}


Table A8. Age dependent taxes

\begin{tabular}{|c|c|c|c|c|c|c|c|c|c|c|c|c|c|c|c|}
\hline Reform & $\begin{array}{l}\text { Flat } \\
\text { tax }\end{array}$ & $\begin{array}{c}\text { Up } 26-46 \\
(\%)\end{array}$ & $\begin{array}{c}\text { Down 46-65 } \\
(\%)\end{array}$ & Hours & $\begin{array}{l}\text { Partici- } \\
\text { pation }\end{array}$ & Budget & $\begin{array}{c}\text { Disposible- } \\
\text { income }\end{array}$ & $\begin{array}{c}\text { Labor } \\
\text { income }\end{array}$ & $\begin{array}{c}\text { Income } \\
\text { tax }\end{array}$ & GINI & D9/D2 & W1 & W2 & W3 & W4 \\
\hline 0 & \multicolumn{3}{|c|}{ Bas: Skatte systemet 2006} & $0.00 \%$ & $0.00 \%$ & $0.00 \%$ & $0.00 \%$ & $0.00 \%$ & $0.00 \%$ & $0.0 \%$ & 2.34 & 16 & 17 & 17 & 21 \\
\hline 1 & $15 \%$ & 1.00 & 1.00 & $3.89 \%$ & $1.11 \%$ & $-6.60 \%$ & $12.46 \%$ & $4.02 \%$ & $-21.12 \%$ & $6.6 \%$ & 2.68 & 1 & 1 & 1 & 1 \\
\hline 2 & $15 \%$ & 1.05 & 1.05 & $3.77 \%$ & $1.05 \%$ & $-6.15 \%$ & $11.87 \%$ & $3.92 \%$ & $-19.93 \%$ & $6.6 \%$ & 2.67 & 2 & 2 & 2 & 2 \\
\hline 3 & $15 \%$ & 1.10 & 1.10 & $3.65 \%$ & $0.98 \%$ & $-5.71 \%$ & $11.28 \%$ & $3.81 \%$ & $-18.74 \%$ & $6.6 \%$ & 2.65 & 3 & 3 & 3 & 3 \\
\hline 4 & $15 \%$ & 1.15 & 1.15 & $3.53 \%$ & $0.92 \%$ & $-5.27 \%$ & $10.70 \%$ & $3.71 \%$ & $-17.56 \%$ & $6.7 \%$ & 2.63 & 5 & 4 & 4 & 4 \\
\hline 5 & $15 \%$ & 1.20 & 1.20 & $3.40 \%$ & $0.85 \%$ & $-4.85 \%$ & $10.10 \%$ & $3.59 \%$ & $-16.39 \%$ & $6.8 \%$ & 2.62 & 6 & 5 & 5 & 5 \\
\hline 6 & $15 \%$ & 1.25 & 1.25 & $3.26 \%$ & $0.77 \%$ & $-4.43 \%$ & $9.51 \%$ & $3.47 \%$ & $-15.23 \%$ & $6.9 \%$ & 2.60 & 7 & 7 & 7 & 6 \\
\hline 7 & $15 \%$ & 1.30 & 1.30 & $3.11 \%$ & $0.68 \%$ & $-4.02 \%$ & $8.91 \%$ & $3.33 \%$ & $-14.08 \%$ & $7.0 \%$ & 2.59 & 8 & 8 & 8 & 7 \\
\hline 8 & $15 \%$ & 1.35 & 1.35 & $2.97 \%$ & $0.60 \%$ & $-3.60 \%$ & $8.33 \%$ & $3.22 \%$ & $-12.92 \%$ & $7.1 \%$ & 2.57 & 9 & 9 & 9 & 8 \\
\hline 9 & $15 \%$ & 1.40 & 1.40 & $2.83 \%$ & $0.52 \%$ & $-3.19 \%$ & $7.74 \%$ & $3.09 \%$ & $-11.77 \%$ & $7.2 \%$ & 2.56 & 10 & 10 & 10 & 9 \\
\hline 10 & $15 \%$ & 1.45 & 1.45 & $2.66 \%$ & $0.42 \%$ & $-2.81 \%$ & $7.14 \%$ & $2.94 \%$ & $-10.65 \%$ & $7.3 \%$ & 2.54 & 11 & 11 & 11 & 11 \\
\hline 11 & $15 \%$ & 1.50 & 1.50 & $2.50 \%$ & $0.32 \%$ & $-2.43 \%$ & $6.55 \%$ & $2.80 \%$ & $-9.52 \%$ & $7.5 \%$ & 2.52 & 12 & 12 & 12 & 12 \\
\hline 12 & $15 \%$ & 1.55 & 1.55 & $2.33 \%$ & $0.21 \%$ & $-2.05 \%$ & $5.96 \%$ & $2.65 \%$ & $-8.41 \%$ & $7.7 \%$ & 2.51 & 13 & 13 & 13 & 13 \\
\hline 13 & $15 \%$ & 1.60 & 1.60 & $2.18 \%$ & $0.13 \%$ & $-1.65 \%$ & $5.38 \%$ & $2.52 \%$ & $-7.27 \%$ & $7.8 \%$ & 2.49 & 14 & 14 & 14 & 14 \\
\hline 14 & $15 \%$ & 1.65 & 1.65 & $1.99 \%$ & $0.00 \%$ & $-1.30 \%$ & $4.78 \%$ & $2.35 \%$ & $-6.19 \%$ & $8.0 \%$ & 2.48 & 15 & 15 & 15 & 15 \\
\hline 15 & $15 \%$ & 1.70 & 1.70 & $1.81 \%$ & $-0.12 \%$ & $-0.94 \%$ & $4.19 \%$ & $2.19 \%$ & $-5.09 \%$ & $8.2 \%$ & 2.47 & 17 & 16 & 16 & 16 \\
\hline 16 & $15 \%$ & 1.75 & 1.75 & $1.58 \%$ & $-0.27 \%$ & $-0.63 \%$ & $3.58 \%$ & $1.98 \%$ & $-4.05 \%$ & $8.5 \%$ & 2.45 & 18 & 18 & 18 & 17 \\
\hline 17 & $15 \%$ & 1.80 & 1.80 & $1.36 \%$ & $-0.43 \%$ & $-0.32 \%$ & $2.98 \%$ & $1.79 \%$ & $-3.00 \%$ & $8.7 \%$ & 2.44 & 19 & 19 & 19 & 18 \\
\hline 18 & $15 \%$ & 1.85 & 1.85 & $1.16 \%$ & $-0.56 \%$ & $0.02 \%$ & $2.39 \%$ & $1.62 \%$ & $-1.94 \%$ & $9.0 \%$ & 2.42 & 20 & 20 & 20 & 19 \\
\hline 19 & $15 \%$ & 1.90 & 1.90 & $0.93 \%$ & $-0.72 \%$ & $0.32 \%$ & $1.80 \%$ & $1.42 \%$ & $-0.90 \%$ & $9.3 \%$ & 2.42 & 21 & 21 & 21 & 20 \\
\hline 20 & $15 \%$ & 1.95 & 1.95 & $0.73 \%$ & $-0.85 \%$ & $0.65 \%$ & $1.22 \%$ & $1.25 \%$ & $0.15 \%$ & $9.5 \%$ & 2.40 & 22 & 22 & 22 & 22 \\
\hline 21 & $15 \%$ & 2.00 & 2.00 & $0.50 \%$ & $-1.00 \%$ & $0.94 \%$ & $0.63 \%$ & $1.05 \%$ & $1.16 \%$ & $9.8 \%$ & 2.39 & 23 & 23 & 23 & 23 \\
\hline 22 & \multicolumn{3}{|c|}{ Extended 2009 in-work taxcredit } & $1.79 \%$ & $1.52 \%$ & $-3.93 \%$ & $5.76 \%$ & $1.38 \%$ & $-11.55 \%$ & $-1.4 \%$ & 2.48 & 4 & 6 & 6 & 10 \\
\hline
\end{tabular}


Table A9. Combinations of tax/benefits

\begin{tabular}{|c|c|c|c|c|c|c|c|c|c|c|c|c|c|c|c|c|c|}
\hline $\begin{array}{l}\text { Refor } \\
\mathrm{m}\end{array}$ & $\begin{array}{l}\text { Top } \\
\text { level }\end{array}$ & Level & $\begin{array}{l}\text { Break } \\
\text { point }\end{array}$ & $\begin{array}{l}\text { Housing } \\
\text { allowance }\end{array}$ & $\begin{array}{l}\text { Credit/ } \\
\text { deduction }\end{array}$ & Hours & $\begin{array}{c}\text { Partici- } \\
\text { pation }\end{array}$ & Budget & $\begin{array}{l}\text { Disposibl } \\
\text { e income }\end{array}$ & $\begin{array}{c}\text { Labor } \\
\text { income }\end{array}$ & $\begin{array}{c}\text { Income } \\
\operatorname{tax}\end{array}$ & GINI & D9/D2 & W 1 & W2 & W3 & W4 \\
\hline 0 & $0 \%$ & $0 \%$ & $0 \%$ & $0 \%$ & 2006 & $0.00 \%$ & $0.00 \%$ & $0.00 \%$ & $0.00 \%$ & $0.00 \%$ & $0.00 \%$ & $0.0 \%$ & 2.34 & 80 & 80 & 80 & 76 \\
\hline 39 & $0 \%$ & $-25 \%$ & $25 \%$ & $50 \%$ & 2009 + age & $2.69 \%$ & $1.54 \%$ & $-4.85 \%$ & $8.31 \%$ & $2.49 \%$ & $-14.97 \%$ & $1.6 \%$ & 2.46 & 17 & 3 & 1 & 4 \\
\hline 79 & $-100 \%$ & $-25 \%$ & $25 \%$ & $50 \%$ & 2009 + age & $2.74 \%$ & $1.54 \%$ & $-4.85 \%$ & $8.46 \%$ & $2.58 \%$ & $-15.11 \%$ & $2.1 \%$ & 2.47 & 21 & 5 & 2 & 2 \\
\hline 59 & $-100 \%$ & $0 \%$ & $25 \%$ & $50 \%$ & $2009+$ age & $2.54 \%$ & $1.53 \%$ & $-4.76 \%$ & $7.90 \%$ & $2.27 \%$ & $-14.48 \%$ & $0.9 \%$ & 2.45 & 18 & 6 & 3 & 6 \\
\hline 77 & $-100 \%$ & $-25 \%$ & $25 \%$ & $50 \%$ & $2009+50 \%$ & $3.06 \%$ & $1.91 \%$ & $-7.51 \%$ & $11.40 \%$ & $2.80 \%$ & $-21.75 \%$ & $1.1 \%$ & 2.47 & 12 & 7 & 5 & 21 \\
\hline 19 & $0 \%$ & $0 \%$ & $25 \%$ & $50 \%$ & $2009+$ age & $2.49 \%$ & $1.53 \%$ & $-4.76 \%$ & $7.72 \%$ & $2.16 \%$ & $-14.31 \%$ & $0.3 \%$ & 2.45 & 22 & 9 & 4 & 13 \\
\hline 37 & $0 \%$ & $-25 \%$ & $25 \%$ & $50 \%$ & $2009+50 \%$ & $3.03 \%$ & $1.91 \%$ & $-7.48 \%$ & $11.27 \%$ & $2.73 \%$ & $-21.61 \%$ & $0.7 \%$ & 2.47 & 11 & 8 & 6 & 24 \\
\hline 69 & $-100 \%$ & $-25 \%$ & $0 \%$ & $50 \%$ & $2009+$ age & $2.18 \%$ & $1.46 \%$ & $-4.47 \%$ & $7.21 \%$ & $2.00 \%$ & $-13.40 \%$ & $1.0 \%$ & 2.42 & 16 & 10 & 9 & 14 \\
\hline 29 & $0 \%$ & $-25 \%$ & $0 \%$ & $50 \%$ & $2009+$ age & $2.10 \%$ & $1.46 \%$ & $-4.44 \%$ & $6.96 \%$ & $1.84 \%$ & $-13.14 \%$ & $0.3 \%$ & 2.42 & 13 & 11 & 12 & 18 \\
\hline 78 & $-100 \%$ & $-25 \%$ & $25 \%$ & $50 \%$ & $2009+100 \%$ & $3.52 \%$ & $2.35 \%$ & $-10.60 \%$ & $14.87 \%$ & $3.11 \%$ & $-29.50 \%$ & $0.1 \%$ & 2.48 & 1 & 1 & 11 & 46 \\
\hline 38 & $0 \%$ & $-25 \%$ & $25 \%$ & $50 \%$ & $2009+100 \%$ & $3.49 \%$ & $2.36 \%$ & $-10.57 \%$ & $14.74 \%$ & $3.05 \%$ & $-29.35 \%$ & $-0.3 \%$ & 2.48 & 2 & 2 & 13 & 50 \\
\hline 57 & $-100 \%$ & $0 \%$ & $25 \%$ & $50 \%$ & $2009+50 \%$ & $2.88 \%$ & $1.90 \%$ & $-7.40 \%$ & $10.87 \%$ & $2.52 \%$ & $-21.14 \%$ & $-0.1 \%$ & 2.45 & 15 & 16 & 16 & 31 \\
\hline 67 & $-100 \%$ & $-25 \%$ & $0 \%$ & $50 \%$ & $2009+50 \%$ & $2.55 \%$ & $1.84 \%$ & $-7.12 \%$ & $10.23 \%$ & $2.27 \%$ & $-20.11 \%$ & $0.0 \%$ & 2.42 & 9 & 14 & 20 & 35 \\
\hline 34 & $0 \%$ & $-25 \%$ & $25 \%$ & $0 \%$ & 2009 + age & $2.82 \%$ & $1.64 \%$ & $-4.66 \%$ & $8.29 \%$ & $2.59 \%$ & $-14.92 \%$ & $1.7 \%$ & 2.47 & 51 & 22 & 7 & 3 \\
\hline 58 & $-100 \%$ & $0 \%$ & $25 \%$ & $50 \%$ & $2009+100 \%$ & $3.36 \%$ & $2.35 \%$ & $-10.48 \%$ & $14.37 \%$ & $2.87 \%$ & $-28.89 \%$ & $-1.0 \%$ & 2.47 & 3 & 4 & 18 & 59 \\
\hline 74 & $-100 \%$ & $-25 \%$ & $25 \%$ & $0 \%$ & $2009+$ age & $2.86 \%$ & $1.64 \%$ & $-4.67 \%$ & $8.43 \%$ & $2.68 \%$ & $-15.05 \%$ & $2.1 \%$ & 2.47 & 52 & 25 & 8 & 1 \\
\hline 54 & $-100 \%$ & $0 \%$ & $25 \%$ & $0 \%$ & 2009 + age & $2.66 \%$ & $1.62 \%$ & $-4.58 \%$ & $7.87 \%$ & $2.37 \%$ & $-14.42 \%$ & $0.9 \%$ & 2.45 & 48 & 24 & 10 & 5 \\
\hline 64 & $-100 \%$ & $-25 \%$ & $0 \%$ & $0 \%$ & 2009 + age & $2.32 \%$ & $1.57 \%$ & $-4.27 \%$ & $7.19 \%$ & $2.11 \%$ & $-13.34 \%$ & $1.0 \%$ & 2.42 & 41 & 26 & 15 & 12 \\
\hline 27 & $0 \%$ & $-25 \%$ & $0 \%$ & $50 \%$ & $2009+50 \%$ & $2.47 \%$ & $1.84 \%$ & $-7.10 \%$ & $9.98 \%$ & $2.12 \%$ & $-19.86 \%$ & $-0.7 \%$ & 2.42 & 10 & 17 & 25 & 43 \\
\hline 17 & $0 \%$ & $0 \%$ & $25 \%$ & $50 \%$ & $2009+50 \%$ & $2.82 \%$ & $1.89 \%$ & $-7.41 \%$ & $10.70 \%$ & $2.40 \%$ & $-20.98 \%$ & $-0.6 \%$ & 2.45 & 19 & 19 & 24 & 36 \\
\hline 73 & $-100 \%$ & $-25 \%$ & $25 \%$ & $0 \%$ & $2009+100 \%$ & $3.62 \%$ & $2.43 \%$ & $-10.44 \%$ & $14.84 \%$ & $3.20 \%$ & $-29.47 \%$ & $0.2 \%$ & 2.48 & 25 & 18 & 19 & 39 \\
\hline 24 & $0 \%$ & $-25 \%$ & $0 \%$ & $0 \%$ & $2009+$ age & $2.23 \%$ & $1.56 \%$ & $-4.25 \%$ & $6.93 \%$ & $1.96 \%$ & $-13.08 \%$ & $0.3 \%$ & 2.42 & 42 & 28 & 17 & 16 \\
\hline 14 & $0 \%$ & $0 \%$ & $25 \%$ & $0 \%$ & 2009 + age & $2.61 \%$ & $1.63 \%$ & $-4.58 \%$ & $7.70 \%$ & $2.26 \%$ & $-14.26 \%$ & $0.4 \%$ & .45 & 54 & 30 & 14 & 10 \\
\hline 49 & $-100 \%$ & $0 \%$ & $0 \%$ & $50 \%$ & $2009+$ age & $1.79 \%$ & $1.44 \%$ & $-4.28 \%$ & $6.27 \%$ & $1.49 \%$ & $-12.28 \%$ & $-0.6 \%$ & 2.39 & 23 & 23 & 32 & 32 \\
\hline 36 & $0 \%$ & $-25 \%$ & $25 \%$ & $50 \%$ & 2009 & $2.48 \%$ & $1.30 \%$ & $-4.47 \%$ & $7.75 \%$ & $2.33 \%$ & $-13.82 \%$ & $1.9 \%$ & 2.46 & 37 & 38 & 26 & 11 \\
\hline 76 & $-100 \%$ & $-25 \%$ & $25 \%$ & $50 \%$ & 2009 & $2.52 \%$ & $1.30 \%$ & $-4.47 \%$ & $7.89 \%$ & $2.42 \%$ & $-13.95 \%$ & $2.3 \%$ & 2.47 & 38 & 40 & 27 & 8 \\
\hline 18 & $0 \%$ & $0 \%$ & $25 \%$ & $50 \%$ & $2009+100 \%$ & $3.31 \%$ & $2.35 \%$ & $-10.48 \%$ & $14.20 \%$ & $2.75 \%$ & $-28.74 \%$ & $-1.4 \%$ & 2.46 & 6 & 13 & 29 & 66 \\
\hline 68 & $-100 \%$ & $-25 \%$ & $0 \%$ & $50 \%$ & $2009+100 \%$ & $3.06 \%$ & $2.30 \%$ & $-10.21 \%$ & $13.76 \%$ & $2.63 \%$ & $-27.93 \%$ & $-1.0 \%$ & 2.44 & 4 & 12 & 30 & 68 \\
\hline 33 & $0 \%$ & $-25 \%$ & $25 \%$ & $0 \%$ & $2009+100 \%$ & $3.59 \%$ & $.43 \%$ & $-10.42 \%$ & $14.71 \%$ & $.13 \%$ & $-29.32 \%$ & $-0.2 \%$ & .48 & 26 & 20 & 23 & 48 \\
\hline 72 & $-100 \%$ & $-25 \%$ & $25 \%$ & $0 \%$ & $2009+50 \%$ & $3.19 \%$ & $2.01 \%$ & $-7.33 \%$ & $11.38 \%$ & $2.90 \%$ & $-21.71 \%$ & $1.1 \%$ & 2.47 & 47 & 33 & 21 & 19 \\
\hline 32 & $0 \%$ & $-25 \%$ & $25 \%$ & $0 \%$ & $2009+50 \%$ & $3.16 \%$ & $2.02 \%$ & $-7.30 \%$ & $11.26 \%$ & $2.84 \%$ & $-21.56 \%$ & $0.7 \%$ & 2.47 & 46 & 34 & 22 & 22 \\
\hline 28 & $0 \%$ & $-25 \%$ & $0 \%$ & $50 \%$ & $2009+100 \%$ & $2.98 \%$ & $2.30 \%$ & $-10.17 \%$ & $13.53 \%$ & $2.50 \%$ & $-27.67 \%$ & $-1.6 \%$ & 2.44 & 5 & 15 & 34 & 72 \\
\hline 56 & $-100 \%$ & $0 \%$ & $25 \%$ & $50 \%$ & 2009 & $2.32 \%$ & $1.29 \%$ & $-4.39 \%$ & $7.34 \%$ & $2.11 \%$ & $-13.32 \%$ & $1.1 \%$ & 2.45 & 36 & 43 & 31 & 17 \\
\hline 9 & $0 \%$ & $0 \%$ & $0 \%$ & $50 \%$ & 2009 + age & $1.69 \%$ & $1.45 \%$ & $-4.25 \%$ & $5.95 \%$ & $1.30 \%$ & $-11.95 \%$ & $-1.4 \%$ & 2.39 & 24 & 31 & 40 & 45 \\
\hline 66 & $-100 \%$ & $-25 \%$ & $0 \%$ & $50 \%$ & 2009 & $1.96 \%$ & $.22 \%$ & $-4.10 \%$ & $6.65 \%$ & $1.84 \%$ & $-12.25 \%$ & $1.2 \%$ & 2.42 & 32 & 45 & 39 & 26 \\
\hline 52 & $-100 \%$ & $0 \%$ & $25 \%$ & $0 \%$ & $2009+50 \%$ & $3.01 \%$ & $2.00 \%$ & $-7.22 \%$ & $10.86 \%$ & $2.63 \%$ & $-21.09 \%$ & $0.0 \%$ & 2.46 & 49 & 37 & 28 & 29 \\
\hline 53 & $-100 \%$ & $0 \%$ & $25 \%$ & $0 \%$ & $2009+100 \%$ & $3.47 \%$ & $2.43 \%$ & $-10.32 \%$ & $14.35 \%$ & $2.95 \%$ & $-28.86 \%$ & $-0.9 \%$ & 2.47 & 28 & 27 & 33 & 56 \\
\hline 16 & $0 \%$ & $0 \%$ & $25 \%$ & $50 \%$ & 2009 & $2.27 \%$ & $1.29 \%$ & $-4.38 \%$ & $7.16 \%$ & $2.00 \%$ & $-13.16 \%$ & $0.5 \%$ & 2.45 & 39 & 48 & 35 & 23 \\
\hline 47 & $-100 \%$ & $0 \%$ & $0 \%$ & $50 \%$ & $2009+50 \%$ & $2.18 \%$ & $1.81 \%$ & $-6.95 \%$ & $9.32 \%$ & $1.77 \%$ & $-19.04 \%$ & $-1.5 \%$ & 2.40 & 14 & 29 & 48 & 61 \\
\hline 26 & $0 \%$ & $-25 \%$ & $0 \%$ & $50 \%$ & 2009 & $1.87 \%$ & $1.22 \%$ & $-4.07 \%$ & $6.39 \%$ & $1.68 \%$ & $-11.99 \%$ & $0.5 \%$ & 2.42 & 33 & 49 & 43 & 28 \\
\hline 62 & $-100 \%$ & $-25 \%$ & $0 \%$ & $0 \%$ & $2009+50 \%$ & $2.69 \%$ & $1.95 \%$ & $-6.93 \%$ & $10.21 \%$ & $2.38 \%$ & $-20.06 \%$ & $0.0 \%$ & 2.43 & 44 & 41 & 36 & 34 \\
\hline 48 & $-100 \%$ & $0 \%$ & $0 \%$ & $50 \%$ & $2009+100 \%$ & $2.72 \%$ & $2.28 \%$ & $-10.03 \%$ & $12.89 \%$ & $2.17 \%$ & $-26.89 \%$ & $-2.4 \%$ & 2.41 & 7 & 21 & 52 & 77 \\
\hline 44 & $-100 \%$ & $0 \%$ & $0 \%$ & $0 \%$ & 2009 + age & $1.92 \%$ & $1.54 \%$ & $-4.09 \%$ & $6.24 \%$ & $1.60 \%$ & $-12.22 \%$ & $-0.6 \%$ & 2.39 & 50 & 44 & 38 & 30 \\
\hline 63 & $-100 \%$ & $-25 \%$ & $0 \%$ & $0 \%$ & $2009+100 \%$ & $3.16 \%$ & $2.38 \%$ & $-10.04 \%$ & $13.73 \%$ & $2.72 \%$ & $-27.90 \%$ & $-0.9 \%$ & 2.44 & 27 & 32 & 44 & 65 \\
\hline 31 & $0 \%$ & $-25 \%$ & $25 \%$ & $0 \%$ & 2009 & $2.63 \%$ & $1.42 \%$ & $-4.27 \%$ & $7.73 \%$ & $2.45 \%$ & $-13.75 \%$ & $1.9 \%$ & 2.47 & 61 & 58 & 41 & 9 \\
\hline 22 & $0 \%$ & $-25 \%$ & $0 \%$ & $0 \%$ & $2009+50 \%$ & $2.61 \%$ & $1.95 \%$ & $-6.91 \%$ & $9.97 \%$ & $2.23 \%$ & $-19.81 \%$ & $-0.6 \%$ & 2.42 & 45 & 46 & 42 & 41 \\
\hline 13 & $0 \%$ & $0 \%$ & $25 \%$ & $0 \%$ & $2009+100 \%$ & $3.41 \%$ & $2.42 \%$ & $-10.32 \%$ & $14.17 \%$ & $2.84 \%$ & $-28.70 \%$ & $-1.4 \%$ & 2.47 & 31 & 35 & 45 & 64 \\
\hline 12 & $0 \%$ & $0 \%$ & $25 \%$ & $0 \%$ & $2009+50 \%$ & $2.96 \%$ & $2.00 \%$ & $-7.23 \%$ & $10.68 \%$ & $2.51 \%$ & $-20.93 \%$ & $-0.5 \%$ & 2.45 & 56 & 50 & 37 & 33 \\
\hline 71 & $-100 \%$ & $-25 \%$ & $25 \%$ & $0 \%$ & 2009 & $2.67 \%$ & $1.42 \%$ & $-4.27 \%$ & $7.88 \%$ & $2.54 \%$ & $-13.89 \%$ & $2.3 \%$ & 2.47 & 63 & 59 & 47 & 7 \\
\hline 51 & $-100 \%$ & $0 \%$ & $25 \%$ & $0 \%$ & 2009 & $2.47 \%$ & $1.41 \%$ & $-4.19 \%$ & $7.32 \%$ & $2.23 \%$ & $-13.26 \%$ & $1.1 \%$ & 2.45 & 59 & 57 & 46 & 15 \\
\hline 7 & $0 \%$ & $0 \%$ & $0 \%$ & $50 \%$ & $2009+50 \%$ & $2.06 \%$ & $1.81 \%$ & $-6.94 \%$ & $9.00 \%$ & $1.57 \%$ & $-18.74 \%$ & $-2.3 \%$ & 2.39 & 20 & 39 & 56 & 71 \\
\hline 23 & $0 \%$ & $-25 \%$ & $0 \%$ & $0 \%$ & $2009+100 \%$ & $3.09 \%$ & $2.38 \%$ & $-10.00 \%$ & $13.50 \%$ & $2.59 \%$ & $-27.63 \%$ & $-1.5 \%$ & 2.44 & 30 & 36 & 51 & 70 \\
\hline
\end{tabular}
(continued) 


\begin{tabular}{|c|c|c|c|c|c|c|c|c|c|c|c|c|c|c|c|c|c|}
\hline 46 & $-100 \%$ & $0 \%$ & $0 \%$ & $50 \%$ & 2009 & $1.56 \%$ & $1.20 \%$ & $-3.92 \%$ & $5.70 \%$ & $1.32 \%$ & $-11.13 \%$ & $-0.4 \%$ & 2.39 & 35 & 53 & 57 & 44 \\
\hline 11 & $0 \%$ & $0 \%$ & $25 \%$ & $0 \%$ & 2009 & $2.42 \%$ & $1.41 \%$ & $-4.19 \%$ & $7.14 \%$ & $2.11 \%$ & $-13.10 \%$ & $0.6 \%$ & 2.45 & 60 & 60 & 50 & 20 \\
\hline 8 & $0 \%$ & $0 \%$ & $0 \%$ & $50 \%$ & $2009+1009$ & $2.61 \%$ & $2.28 \%$ & $-10.02 \%$ & $12.59 \%$ & $1.97 \%$ & $-26.61 \%$ & $-3.2 \%$ & 2.41 & 8 & 42 & 61 & 80 \\
\hline 4 & $0 \%$ & $0 \%$ & $0 \%$ & $0 \%$ & $2009+$ age & $1.82 \%$ & $1.55 \%$ & $-4.07 \%$ & $5.92 \%$ & $1.40 \%$ & $-11.90 \%$ & $-1.4 \%$ & 2.39 & 55 & 51 & 49 & 37 \\
\hline 61 & $-100 \%$ & $-25 \%$ & $0 \%$ & $0 \%$ & 2009 & $2.12 \%$ & $1.35 \%$ & $-3.89 \%$ & $6.64 \%$ & $1.96 \%$ & $-12.18 \%$ & $1.2 \%$ & 2.42 & 57 & 61 & 54 & 25 \\
\hline 21 & $0 \%$ & $-25 \%$ & $0 \%$ & $0 \%$ & 2009 & $2.03 \%$ & $1.34 \%$ & $-3.86 \%$ & $6.38 \%$ & $1.81 \%$ & $-11.92 \%$ & $0.5 \%$ & 2.42 & 58 & 62 & 55 & 27 \\
\hline 42 & $-100 \%$ & $0 \%$ & $0 \%$ & $0 \%$ & $2009+50 \%$ & $2.31 \%$ & $1.91 \%$ & $-6.77 \%$ & $9.29 \%$ & $1.88 \%$ & $-19.00 \%$ & $-1.5 \%$ & 2.40 & 43 & 52 & 53 & 58 \\
\hline 43 & $-100 \%$ & $0 \%$ & $0 \%$ & $0 \%$ & $2009+1009$ & $2.83 \%$ & $2.36 \%$ & $-9.86 \%$ & $12.87 \%$ & $2.27 \%$ & $-26.85 \%$ & $-2.3 \%$ & 2.42 & 29 & 47 & 58 & 75 \\
\hline 6 & $0 \%$ & $0 \%$ & $0 \%$ & $50 \%$ & 2009 & $1.47 \%$ & $1.21 \%$ & $-3.89 \%$ & $5.39 \%$ & $1.14 \%$ & $-10.81 \%$ & $-1.2 \%$ & 2.39 & 40 & 56 & 60 & 55 \\
\hline 41 & $-100 \%$ & $0 \%$ & $0 \%$ & $0 \%$ & 2009 & $1.71 \%$ & $1.32 \%$ & $-3.72 \%$ & $5.68 \%$ & $1.44 \%$ & $-11.07 \%$ & $-0.4 \%$ & 2.39 & 62 & 63 & 62 & 40 \\
\hline 3 & $0 \%$ & $0 \%$ & $0 \%$ & $0 \%$ & $2009+1009$ & $2.72 \%$ & $2.36 \%$ & $-9.86 \%$ & $12.56 \%$ & $2.06 \%$ & $-26.57 \%$ & $-3.1 \%$ & 2.41 & 34 & 54 & 63 & 79 \\
\hline 2 & $0 \%$ & $0 \%$ & $0 \%$ & $0 \%$ & $2009+50 \%$ & $2.19 \%$ & $1.91 \%$ & $-6.76 \%$ & $8.98 \%$ & $1.68 \%$ & $-18.70 \%$ & $-2.3 \%$ & 2.39 & 53 & 55 & 59 & 69 \\
\hline 1 & $0 \%$ & $0 \%$ & $0 \%$ & $0 \%$ & 2009 & $1.61 \%$ & $1.33 \%$ & $-3.69 \%$ & $5.37 \%$ & $1.25 \%$ & $-10.75 \%$ & $-1.2 \%$ & 2.39 & 64 & 64 & 64 & 52 \\
\hline 55 & $-100 \%$ & $0 \%$ & $25 \%$ & $50 \%$ & 2006 & $0.68 \%$ & $-0.07 \%$ & $-0.70 \%$ & $1.96 \%$ & $0.85 \%$ & $-2.55 \%$ & $2.5 \%$ & 2.41 & 67 & 65 & 65 & 53 \\
\hline 75 & $-100 \%$ & $-25 \%$ & $25 \%$ & $50 \%$ & 2006 & $0.88 \%$ & $-0.06 \%$ & $-0.79 \%$ & $2.52 \%$ & $1.16 \%$ & $-3.18 \%$ & $3.8 \%$ & 2.42 & 71 & 68 & 67 & 47 \\
\hline 15 & $0 \%$ & $0 \%$ & $25 \%$ & $50 \%$ & 2006 & $0.63 \%$ & $-0.06 \%$ & $-0.70 \%$ & $1.78 \%$ & $0.73 \%$ & $-2.39 \%$ & $1.9 \%$ & 2.41 & 68 & 66 & 66 & 57 \\
\hline 35 & $0 \%$ & $-25 \%$ & $25 \%$ & $50 \%$ & 2006 & $0.84 \%$ & $-0.06 \%$ & $-0.78 \%$ & $2.38 \%$ & $1.07 \%$ & $-3.04 \%$ & $3.3 \%$ & 2.42 & 72 & 69 & 68 & 49 \\
\hline 70 & $-100 \%$ & $-25 \%$ & $25 \%$ & $0 \%$ & 2006 & $1.06 \%$ & $0.09 \%$ & $-0.56 \%$ & $2.50 \%$ & $1.29 \%$ & $-3.09 \%$ & $3.7 \%$ & 2.43 & 79 & 75 & 69 & 38 \\
\hline 30 & $0 \%$ & $-25 \%$ & $25 \%$ & $0 \%$ & 2006 & $1.02 \%$ & $0.09 \%$ & $-0.54 \%$ & $2.36 \%$ & $1.21 \%$ & $-2.95 \%$ & $3.3 \%$ & 2.42 & 78 & 76 & 70 & 42 \\
\hline 25 & $0 \%$ & $-25 \%$ & $0 \%$ & $50 \%$ & 2006 & $0.25 \%$ & $-0.13 \%$ & $-0.37 \%$ & $1.04 \%$ & $0.45 \%$ & $-1.23 \%$ & $1.9 \%$ & 2.37 & 65 & 67 & 71 & 67 \\
\hline 50 & $-100 \%$ & $0 \%$ & $25 \%$ & $0 \%$ & 2006 & $0.86 \%$ & $0.08 \%$ & $-0.48 \%$ & $1.94 \%$ & $0.98 \%$ & $-2.47 \%$ & $2.4 \%$ & 2.41 & 75 & 73 & 72 & 51 \\
\hline 65 & $-100 \%$ & $-25 \%$ & $0 \%$ & $50 \%$ & 2006 & $0.32 \%$ & $-0.13 \%$ & $-0.42 \%$ & $1.29 \%$ & $0.58 \%$ & $-1.51 \%$ & $2.7 \%$ & 2.38 & 66 & 70 & 74 & 63 \\
\hline 10 & $0 \%$ & $0 \%$ & $25 \%$ & $0 \%$ & 2006 & $0.81 \%$ & $0.08 \%$ & $-0.47 \%$ & $1.76 \%$ & $0.87 \%$ & $-2.30 \%$ & $1.9 \%$ & 2.41 & 74 & 74 & 73 & 54 \\
\hline 20 & $0 \%$ & $-25 \%$ & $0 \%$ & $0 \%$ & 2006 & $0.44 \%$ & $0.03 \%$ & $-0.13 \%$ & $1.03 \%$ & $0.60 \%$ & $-1.13 \%$ & $1.9 \%$ & 2.38 & 73 & 77 & 75 & 62 \\
\hline 60 & $-100 \%$ & $-25 \%$ & $0 \%$ & $0 \%$ & 2006 & $0.51 \%$ & $0.03 \%$ & $-0.18 \%$ & $1.28 \%$ & $0.73 \%$ & $-1.41 \%$ & $2.6 \%$ & 2.38 & 76 & 78 & 76 & 60 \\
\hline 45 & $-100 \%$ & $0 \%$ & $0 \%$ & $50 \%$ & 2006 & $-0.08 \%$ & $-0.16 \%$ & $-0.25 \%$ & $0.34 \%$ & $0.06 \%$ & $-0.40 \%$ & $1.0 \%$ & 2.35 & 69 & 71 & 77 & 74 \\
\hline 5 & $0 \%$ & $0 \%$ & $0 \%$ & $50 \%$ & 2006 & $-0.20 \%$ & $-0.16 \%$ & $-0.25 \%$ & $0.01 \%$ & $-0.16 \%$ & $-0.11 \%$ & $0.0 \%$ & 2.34 & 70 & 72 & 78 & 78 \\
\hline 40 & $-100 \%$ & $0 \%$ & $0 \%$ & $0 \%$ & 2006 & $0.12 \%$ & $0.00 \%$ & $0.00 \%$ & $0.33 \%$ & $0.22 \%$ & $-0.30 \%$ & $0.9 \%$ & 2.35 & 77 & 79 & 79 & 73 \\
\hline
\end{tabular}


Table A10. Combinations of tax/benefits using 2009 years in-work tax credit and basic deduction

\begin{tabular}{|c|c|c|c|c|c|c|c|c|c|c|c|c|c|c|c|c|c|}
\hline Reform & $\begin{array}{l}\text { Top } \\
\text { level }\end{array}$ & Level & $\begin{array}{l}\text { Break } \\
\text { point }\end{array}$ & $\begin{array}{c}\text { Bostads- } \\
\text { bidrag }\end{array}$ & $\begin{array}{l}\text { Taxcredit } \\
\text { and basic } \\
\text { deduction }\end{array}$ & Hours & $\begin{array}{l}\text { Partici- } \\
\text { pation }\end{array}$ & Budget & $\begin{array}{c}\text { Disposible } \\
\text { income }\end{array}$ & $\begin{array}{l}\text { Labor } \\
\text { income }\end{array}$ & $\begin{array}{c}\text { Income } \\
\text { tax }\end{array}$ & GINI & D9/D2 & W1 & W2 & W3 & W4 \\
\hline 0 & $0 \%$ & $0 \%$ & $0 \%$ & $0 \%$ & 2006 & $0.00 \%$ & $0.00 \%$ & $0.00 \%$ & $0.00 \%$ & $0.00 \%$ & $0.00 \%$ & $0.0 \%$ & 2.34 & 80 & 80 & 80 & 76 \\
\hline 6 & $0 \%$ & $-25 \%$ & $25 \%$ & $50 \%$ & 2009 & $2.48 \%$ & $1.30 \%$ & $-4.47 \%$ & $7.75 \%$ & $2.33 \%$ & $-13.82 \%$ & $1.9 \%$ & 2.46 & 37 & 38 & 26 & 11 \\
\hline 1 & $0 \%$ & $-25 \%$ & $25 \%$ & $50 \%$ & 2009 & $2.52 \%$ & $1.30 \%$ & $-4.47 \%$ & $7.89 \%$ & $2.42 \%$ & $-13.95 \%$ & $2.3 \%$ & 2.47 & 38 & 40 & 27 & 8 \\
\hline 46 & $-100 \%$ & $0 \%$ & $25 \%$ & $50 \%$ & 2009 & $2.32 \%$ & $1.29 \%$ & $-4.39 \%$ & $7.34 \%$ & $2.11 \%$ & $-13.32 \%$ & $1.1 \%$ & 2.45 & 36 & 43 & 31 & 17 \\
\hline 41 & $-100 \%$ & $-25 \%$ & $0 \%$ & $50 \%$ & 2009 & $1.96 \%$ & $1.22 \%$ & $-4.10 \%$ & $6.65 \%$ & $1.84 \%$ & $-12.25 \%$ & $1.2 \%$ & 2.42 & 32 & 45 & 39 & 26 \\
\hline 26 & $0 \%$ & $0 \%$ & $25 \%$ & $50 \%$ & 2009 & $2.27 \%$ & $1.29 \%$ & $-4.38 \%$ & $7.16 \%$ & $2.00 \%$ & $-13.16 \%$ & $0.5 \%$ & 2.45 & 39 & 48 & 35 & 23 \\
\hline 21 & $0 \%$ & $-25 \%$ & $0 \%$ & $50 \%$ & 2009 & $1.87 \%$ & $1.22 \%$ & $-4.07 \%$ & $6.39 \%$ & $1.68 \%$ & $-11.99 \%$ & $0.5 \%$ & 2.42 & 33 & 49 & 43 & 28 \\
\hline 66 & $-100 \%$ & $-25 \%$ & $25 \%$ & $0 \%$ & 2009 & $2.63 \%$ & $1.42 \%$ & $-4.27 \%$ & $7.73 \%$ & $2.45 \%$ & $-13.75 \%$ & $1.9 \%$ & 2.47 & 61 & 58 & 41 & 9 \\
\hline 61 & $-100 \%$ & $-25 \%$ & $25 \%$ & $0 \%$ & 2009 & $2.67 \%$ & $1.42 \%$ & $-4.27 \%$ & $7.88 \%$ & $2.54 \%$ & $-13.89 \%$ & $2.3 \%$ & 2.47 & 63 & 59 & 47 & 7 \\
\hline 16 & $0 \%$ & $0 \%$ & $25 \%$ & $0 \%$ & 2009 & $2.47 \%$ & $1.41 \%$ & $-4.19 \%$ & $7.32 \%$ & $2.23 \%$ & $-13.26 \%$ & $1.1 \%$ & 2.45 & 59 & 57 & 46 & 15 \\
\hline 56 & $-100 \%$ & $0 \%$ & $0 \%$ & $50 \%$ & 2009 & $1.56 \%$ & $1.20 \%$ & $-3.92 \%$ & $5.70 \%$ & $1.32 \%$ & $-11.13 \%$ & $-0.4 \%$ & 2.39 & 35 & 53 & 57 & 44 \\
\hline 11 & $0 \%$ & $0 \%$ & $25 \%$ & $0 \%$ & 2009 & $2.42 \%$ & $1.41 \%$ & $-4.19 \%$ & $7.14 \%$ & $2.11 \%$ & $-13.10 \%$ & $0.6 \%$ & 2.45 & 60 & 60 & 50 & 20 \\
\hline 51 & $-100 \%$ & $-25 \%$ & $0 \%$ & $0 \%$ & 2009 & $2.12 \%$ & $1.35 \%$ & $-3.89 \%$ & $6.64 \%$ & $1.96 \%$ & $-12.18 \%$ & $1.2 \%$ & 2.42 & 57 & 61 & 54 & 25 \\
\hline 36 & $0 \%$ & $-25 \%$ & $0 \%$ & $0 \%$ & 2009 & $2.03 \%$ & $1.34 \%$ & $-3.86 \%$ & $6.38 \%$ & $1.81 \%$ & $-11.92 \%$ & $0.5 \%$ & 2.42 & 58 & 62 & 55 & 27 \\
\hline 76 & $-100 \%$ & $0 \%$ & $0 \%$ & $50 \%$ & 2009 & $1.47 \%$ & $1.21 \%$ & $-3.89 \%$ & $5.39 \%$ & $1.14 \%$ & $-10.81 \%$ & $-1.2 \%$ & 2.39 & 40 & 56 & 60 & 55 \\
\hline 31 & $0 \%$ & $0 \%$ & $0 \%$ & $0 \%$ & 2009 & $1.71 \%$ & $1.32 \%$ & $-3.72 \%$ & $5.68 \%$ & $1.44 \%$ & $-11.07 \%$ & $-0.4 \%$ & 2.39 & 62 & 63 & 62 & 40 \\
\hline 71 & $-100 \%$ & $0 \%$ & $0 \%$ & $0 \%$ & 2009 & $1.61 \%$ & $1.33 \%$ & $-3.69 \%$ & $5.37 \%$ & $1.25 \%$ & $-10.75 \%$ & $-1.2 \%$ & 2.39 & 64 & 64 & 64 & 52 \\
\hline
\end{tabular}

